\title{
\#EdTechHub
}

Realising the potential of technology in education

\section{Rolling out a national virtual learning environment}

Taskeen Adam, Björn Haßler, Chris McBurnie

EdTech Hub, https://edtechhub.org Helpdesk Request Response No. 22 2020-07-01

DOI: 10.5281/zenodo.3406132 


\section{About this document}

Recommende Taskeen Adam, Björn Haßler, Chris McBurnie (2020). Rolling out a d citation. national virtual learning environment (EdTech Hub Helpdesk Response No. 22). DOI: 10.5281/zenodo.3406132. Available under Creative Commons Attribution 4.0 International, https://creativecommons.org/licenses/by/4.0_.

Licence. Creative Commons Attribution 4.0 International

https://creativecommons.org/licenses/by/4.0/.

You - dear readers - are free to share (copy and redistribute the material in any medium or format) and adapt (remix, transform, and build upon the material) for any purpose, even commercially. You must give appropriate credit, provide a link to the license, and indicate if changes were made. You may do so in any reasonable manner, but not in any way that suggests the licensor endorses you or your use.

Creative Commons Acknowledgement
This document re-uses some content from:

Christopher McBurnie (2020). The use of virtual learning environments and learning management systems during the COVID-19 pandemic. (EdTech Hub Helpdesk Response No. 07). DOI: 10.5281/zenodo.3805843. Available from https://docs.edtechhub.org/lib/53YEZE6A. Available under Creative Commons Attribution 4.0 International, https://creativecommons.org/licenses/by/4.0/.

Identifiers. 2405685:KWJRW62J; 10.5281/zenodo.3406132

Internal use. https://docs.google.com/document/d/1IMAWQKcCxVAn6ISVLxuM4H n2PIn7mSyzfKvZ47-Zz6U/edit\#

Notes. You can contact the EdTech Hub here: https://edtechhub.org/hello/. 


\section{Introduction}

Since the onset of the COVID-19 pandemic, education planners ${ }^{1}$ have sought to find ways to ensure educational continuity and mitigate learning loss. One approach that has been considered is setting up Virtual Learning Environments (VLES). This technical note aims to inform the design and implementation of a VLE at a national level for basic education.

A VLE is a virtual space designed to support teaching and learning and can resemble anything from a curated content repository to a synchronous video-enabled learning space. VLEs can be set up for use in school or out of school. They allow both teachers and students to gain access to educational tools and resources. During the current pandemic, VLEs can provide out-of-school students with an alternative platform to access quality educational content and to pursue national learning objectives.

As this note focuses on rolling out a national VLE, its recommendations differ from recommendations for a VLE developed for a specific school or course (in the case of higher education). ${ }^{2}$ The terms 'virtual learning environment' and 'learning management system' (LMS) are commonly used interchangeably. We will use the term 'virtual learning environment' throughout this technical note. The term 'VLE platform' is used when referring to the software or back-end development tools used such as Moodle, Canvas, Google Classroom or Kolibri). The term 'VLE' refers to an instance where the VLE platform is used and populated with content for a particular purpose such as $\underline{\text { Uganda's }}$ e-learning platform on Kolibri. ${ }^{3}$

Before rolling out a VLE, education planners should consider whether a VLE is the best way to address learning losses due to the pandemic. Many students in low- and middle-income countries may not benefit from VLEs due to poor connectivity and a lack of technological hardware. Recent data from Senegal (^Le Nestour, et al., 2020), for instance, indicates that less than $1 \%$ of learners have used online courses to pursue education since the beginning of the health crisis. There is also further evidence from Bangladesh, Kenya and other countries which suggest that high aspirations for digital or online learning during COVID are not being actualised ( programme implementers ${ }^{4}$ need to consider how marginalised children will access VLEs, how content relates to the curriculum and how to support student engagement.

This note serves to support education planners in evaluating whether or not a national VLE is the most effective way to proceed given their circumstances. Furthermore, there are many types of VLEs and many configurations for setting them up. Before

\footnotetext{
${ }^{1}$ In this technical note, we use 'education planners' to refer to high-level decision makers such as decision makers in the ministry of education or policy advisors.

${ }^{2}$ In VLE implementations at a school or university course level, the educator and / or educational institution is responsible for the content design and curation, whereas at a national level, this is a task commissioned by the ministry of education.

${ }^{3}$ http://e-learning.education.go.ug/en/learn/\#/topics

${ }^{4}$ In this technical note, we use 'implementers' as a general term that refers to all stakeholders involved in the development of a VLE. These stakeholders include policymakers, policy advisers, educators, curriculum planners, instructional designers and more.
} 
proceeding, the problem that is being responded to needs to properly be defined and investigated. Programme implementers need to think about what purpose a VLE will serve in their specific context.

The timeline for setting up the VLE is also important to consider. When considering emergency responses for education during the COVID-19 pandemic, interventions that will help build long-term capacity for distance education should be prioritised. If a country does not currently have a national VLE, or does not have curated digital content, it may be best to first aim for development of curated content as a short-term goal and then development of a VLE as a medium-term goal. This is to avoid a rushed response and investment before properly interrogating the problem at hand.

As this technical note focuses solely on setting up a national VLE, we recommend reading our technical note on $\hat{\imath}$ the use of virtual learning environments and learning management systems during the COVID-19 pandemic (McBurnie, 2020). In that technical note, we unpacked a more holistic understanding of VLEs including:

- what VLEs are and what purposes they serve;

- various VLE typologies;

- considerations for selecting a VLE platform;

- comparisons of various VLE platforms.

In recommending how to best set up a national VLE, this document outlines an agile development approach and is structured as follows:

1. Essential knowledge on VLEs;

2. An agile approach to setting up a national VLE;

3. Discovery: investigating the problem;

4. Iterative development: alpha, beta and live. 


\section{Essential knowledge on VLEs}

In this section we outline some essential knowledge on VLEs.

\subsection{What is a VLE?}

A VLE is a virtual space designed to support teaching and learning. VLEs have various typologies (^McBurnie, 2020), extending from being a repository of content to a synchronous virtual learning platform. VLEs may offer a range of functionalities such as

- giving teachers and students access to curated educational resources in the form of text, audio or video;

- scaffolding and scheduling learning;

- facilitating communication between students, parents and teachers;

- facilitating discussion between users in discussion forums;

- administering exercises and quizzes;

- conducting formative and summative assessments;

- monitoring student progress;

- providing infrastructure for synchronous virtual lessons.

It is important to note that a VLE can be used in-school for blending learning activities as well as out-of-school for learning from home.

\subsection{How does a VLE work in under-resourced contexts?}

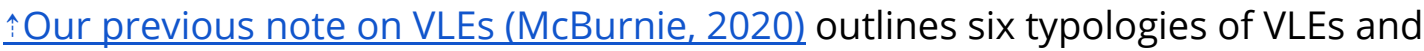
recommends that education implementers consider a typology that is context appropriate. This is important to note as education implementers may want to utilise the latest technologies or try to keep up with other countries who have differing contexts. In doing so, they may develop interventions that look glamorous but are unusable by the majority of the population.

For a national VLE to be rolled out in a context that has under-resourced areas, we recommend using an asynchronous platform with offline capability as it will increase accessibility to the most users. As Kolibri is a platform designed to be used offline, it's architecture is used to illustrate the main features of this type of VLE platform. Figure 1 shows the architecture of the Kolibri learning platform. To our knowledge, such

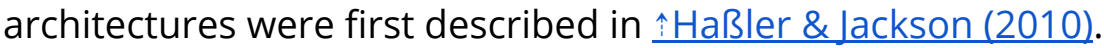




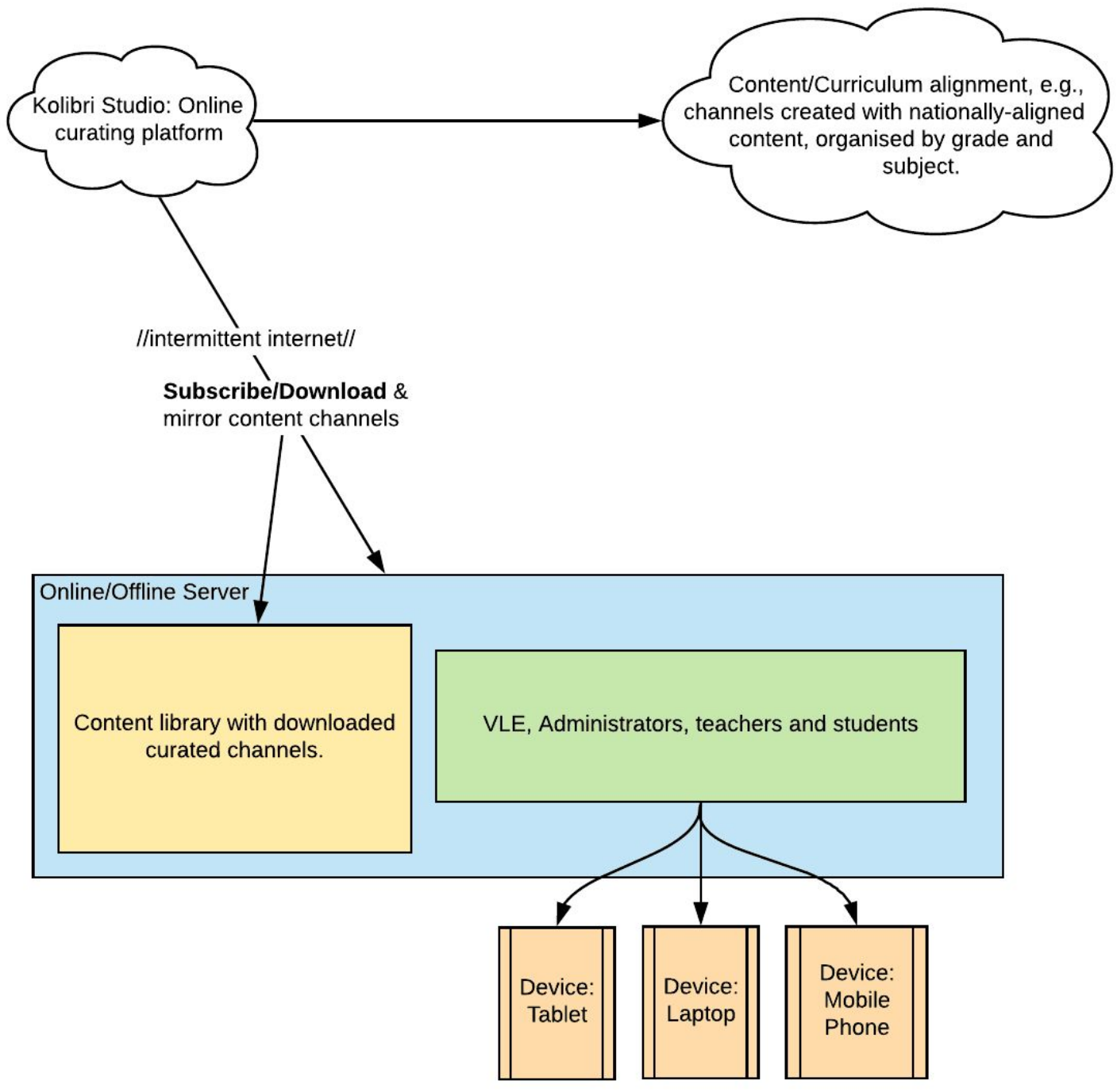

Educators or digital content designers can use the Kolibri Studio tool to curate content into 'channels' that align with local curriculum standards. The channels can be curated into subjects and grades. These channels are then downloaded or subscribed to in the content library of the local server. A local server could be a computer or even a Raspberry Pi which has Wifi capabilities. After the content is downloaded, the server does not need to be online, except for maintenance and updating content channels. Teachers and students also do not need the internet and can access the content over a wireless local area network as long as they are in close proximity to the server. Thus, no data costs are incurred by the teachers and students.

In rolling out a national VLE, the content curation process would be done by a team of educators, curriculum specialists and digital content designers commissioned by the ministry of education. In the Kolibri application, educators can then develop lessons with content from national curriculum channels or Kolibri's open content library according to their teaching schedule. 


\subsection{What are the various scenarios for using a VLE?}

VLEs can be configured to work differently in different contexts such as for school use or for out-of-school use. The configuration will also depend on access to the internet.

We have outlined four main scenarios of how a national VLE roll-out may be implemented:

1. School-based, offline;

2. Student-led, community-based, offline;

3. Teacher-supported, community-based, partially-online scenario;

4. Teacher-supported, out-of-school, fully-online.

The four scenarios are not mutually exclusive; one scenario can easily be turned into others when additional infrastructure becomes available. Ideally, a combination of all four configurations would best suit the diverse needs and contexts of teachers, students and parents. The following subsections unpack the four scenarios.

\subsubsection{School-based, offline scenario}

The main benefit of a school-based VLE with offline functionality is that teachers and students at the school do not need the internet to access the VLE. This provides a more reliable, lower-cost means of connecting to resources. Such an offline VLE can support teachers with access to curated content and lesson plans; it can also facilitate students assessment and thereby provide additional insights about student progress to teachers. Teachers may use this content to

1. plan their usual non-digital classes as well as

2. use the content (lessons, exercises, quizzes, etc.) as part of a blended learning approach.

Where such blended learning is possible, students access lessons and exercises on a device, in class, as part of a lesson planned by the teacher. We note that this is not the same as what is normally understood to be 'e-learning': The students may be using the devices to investigate, stimulating dialogue and collaboration, rather than undertake individual learning. In summary, students can benefit in two ways:

- through the teacher drawing on the content for lesson preparation (teaching better lessons), or

- by directly accessing the content and integrating digital aspects into their learning (including the completion of digital assignments).

Kolibri is a VLE designed for offline use and we now turn to its features. Using Kolibri, teachers can enrol students in classes. In classes, teachers can share resources (such as exercises), offering students scaffolding within a sequence of lessons. Teachers managing specific classes are able to track the content students have accessed, the exercises attempted and the subject areas where students have difficulty. Through these assessment outcomes, teachers are able to develop a better picture of the achievement of their students, and provide targeted support for struggling learners. 
Figure 2 (below) outlines the process of how a school-based, offline scenario works. Figure 3 (below) outlines the configuration of a school-based, offline scenario.

In this configuration, both the teachers, students and server are in school. Channels from the content server are downloaded and stored offline on the server. Neither the students nor teachers need the internet to access the server as they can connect to it via a local connection because they are in close proximity to it. 
Figure 2. Process for school-based, offline scenario
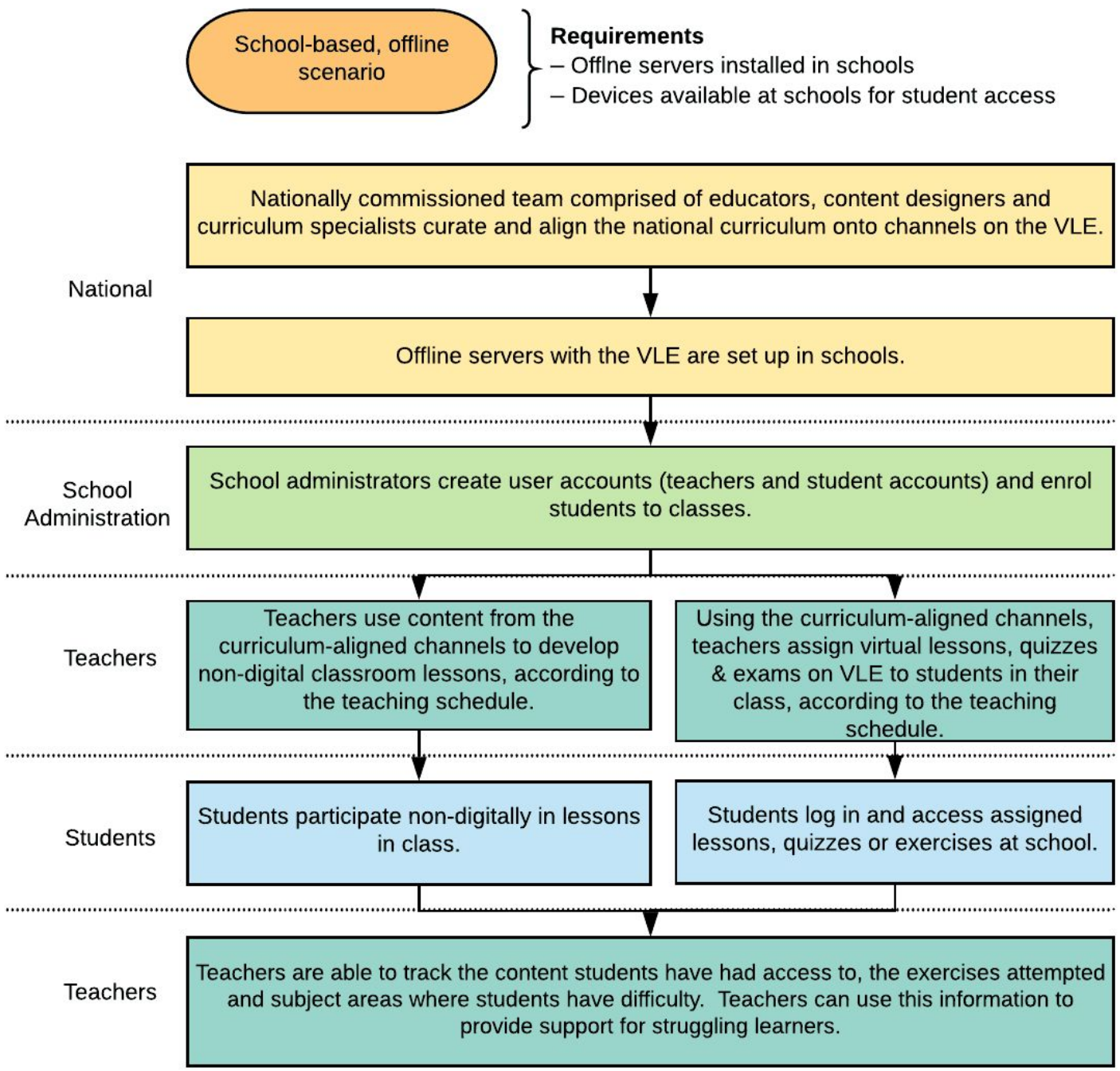

\section{Figure 3. School-based, offline configuration}

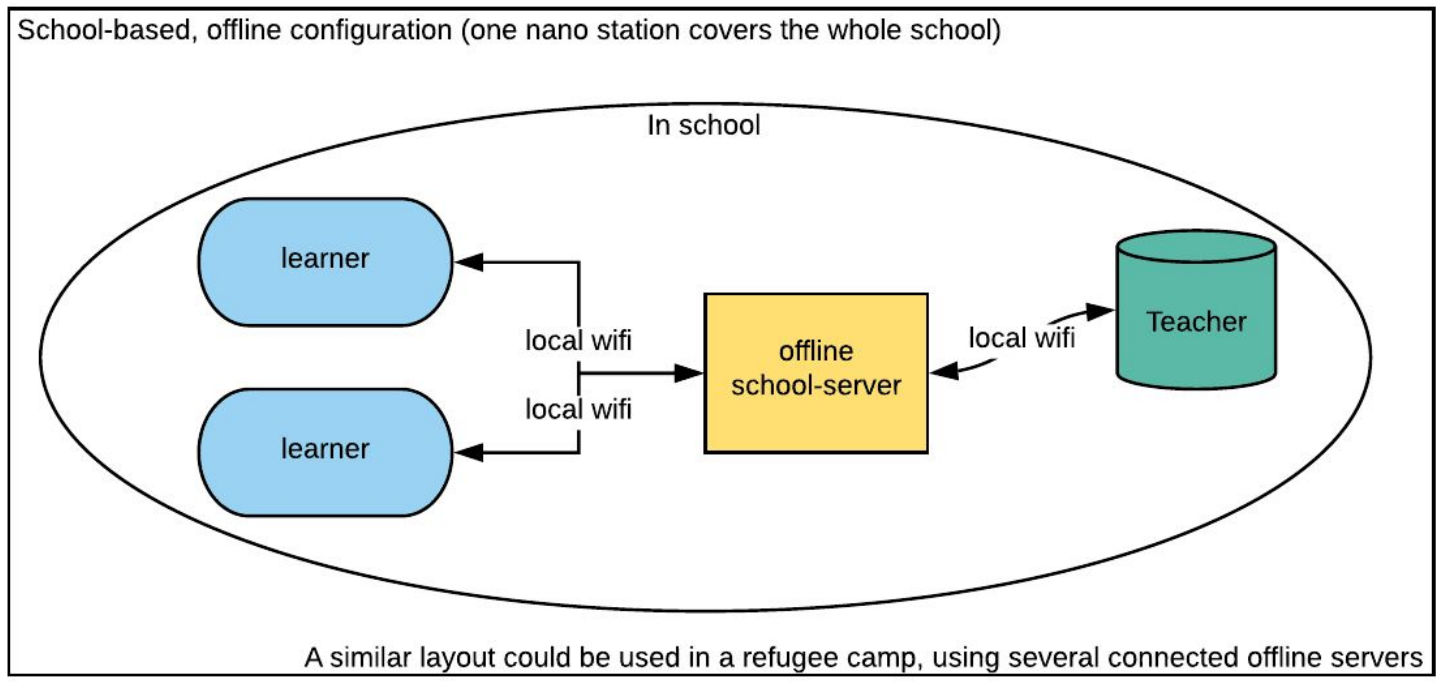




\subsubsection{Student-led, community-based, offline scenario}

For an offline system to work out of school, such as in the case of COVID-19, offline local servers, with the VLE, need to be set up around communities such as in community centres or cafes. These servers could be low-cost, single-board computers ${ }^{5}$ that have the content downloaded onto them. The internet is only needed in the initial set-up phase and if further updating is required. Updating can also be done via a USB that would have the updated content downloaded on it. The server functions as a source of curated, nationally-aligned content for students to access directly by themselves or with the support of their parents or community members. Neither the student nor the server would need access to the internet. Progress can be self-tracked but would not be sent to a teacher over the internet. Usage data can, however, be collected on a USB.

If using Kolibri, for example, students can access content that is either curated to the national curriculum standards or subscribe to other available content on Kolibri. In this instance, students can access content in a non-formal situation, studying as and when they are able to. For example, when the student has been given a specific assignment or is revising for a test or exam, they can go through example questions of national exams that have been added to the accessible channels.

Figure 4 (below) outlines the process of how a student-led, community-based scenario would work and Figure 5 (below) outlines the configuration of a community-based, offline scenario.

In this configuration, the servers with the VLE are installed in multiple locations within a community, creating local networks. Students go to these locations and, with the support of their parents or community members, they connect locally to the server to access the VLE. Students need to connect with their own devices such as tablets and mobile phones, or with devices provided by the community centres.

\footnotetext{
${ }^{5}$ Such as the Raspberry Pi: https://www.raspberrypi.org/
} 


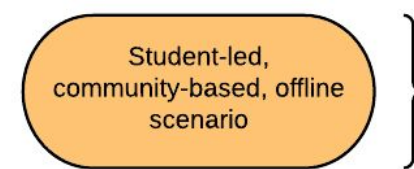

Requirements

- Offline servers installed in community centres/cafes.

- Students to bring their own device or use devices provided by community centres/cafes.

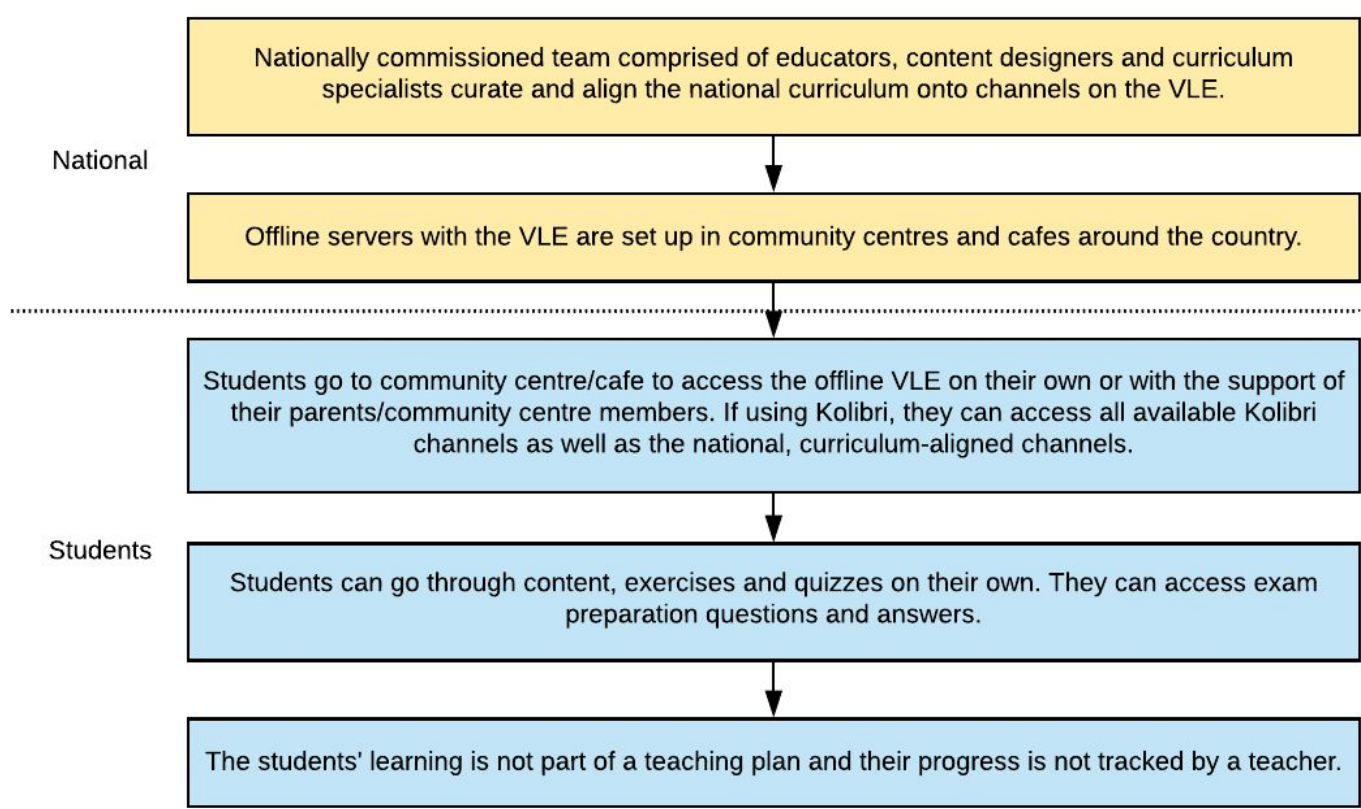

\section{Figure 5. Community-based, offline configuration}

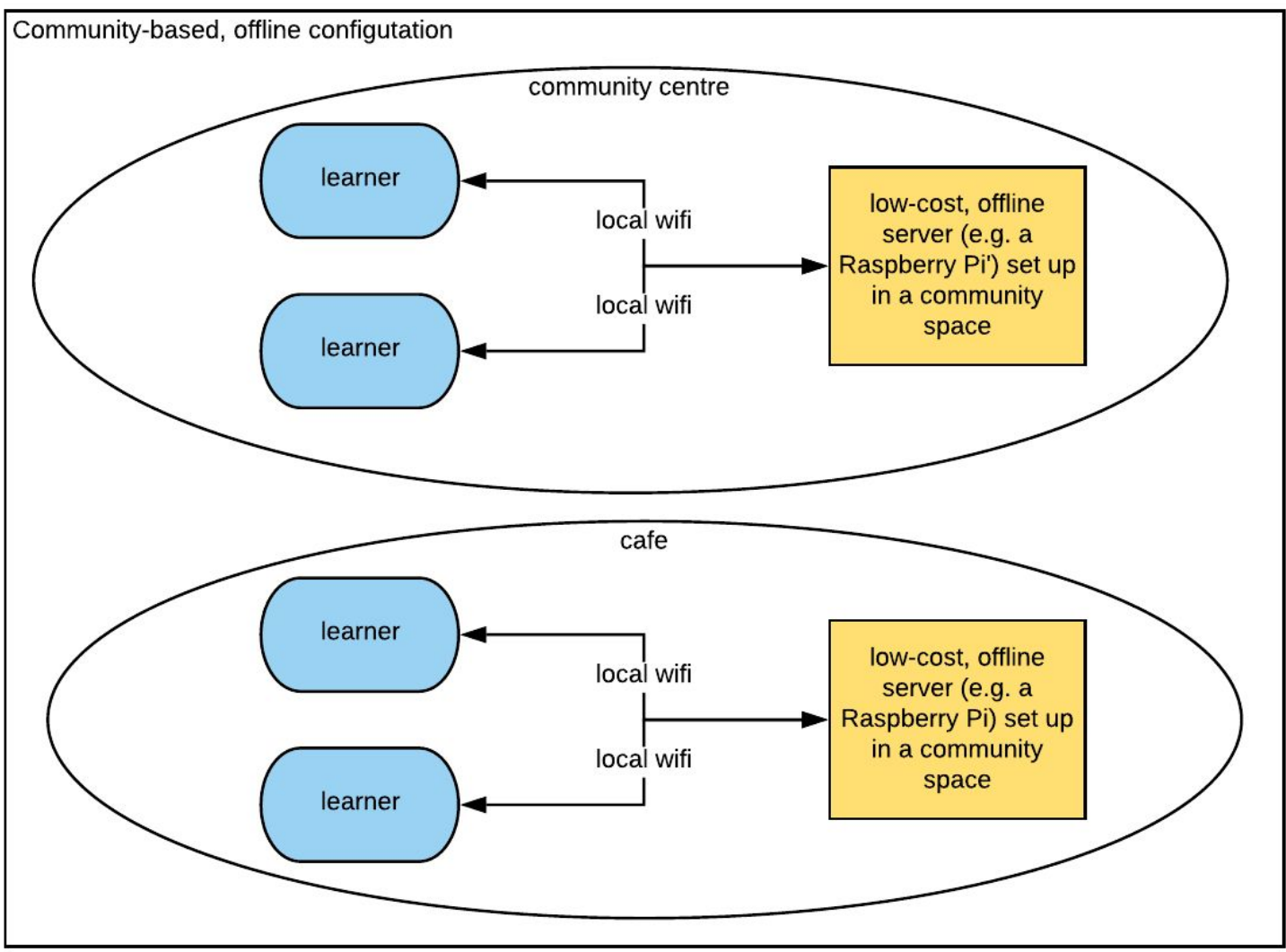




\subsubsection{Teacher-supported, out-of-school, intermittent connectivity scenario}

Where intermittent connectivity is available, a VLE could be set up locally (in community centres or cafes), which periodically accesses the internet. However, the configuration is more complicated. In this scenario, teachers are able to set lessons and exercises as well as track student progress. The server would need to connect to the internet at some point in the day to synchronise the content that the teacher has uploaded. Students, however, would not need the internet to connect to the community server.

Figure 6 (below) outlines the process of how a teacher supported, community-based scenario with intermittent internet connectivity works. Figure 7 (below) outlines the configuration of a VLE that is teacher-supported and community-based, utilising intermittent connectivity.

In this configuration, a teacher with a reliable internet connection would set classes on a centralised server for students enrolled. The centralised server will update lessons at local servers set up in community spaces when these spaces connect to the internet. Students can access content here. When students progress and complete exercises, servers set up in community spaces will return student data back to the centralised server for teachers to review when there is internet connection. The syncing between the centralised server and the community-based servers could happen once a day. 
Figure 6. Process for teacher-supported, community-based, partially online scenario

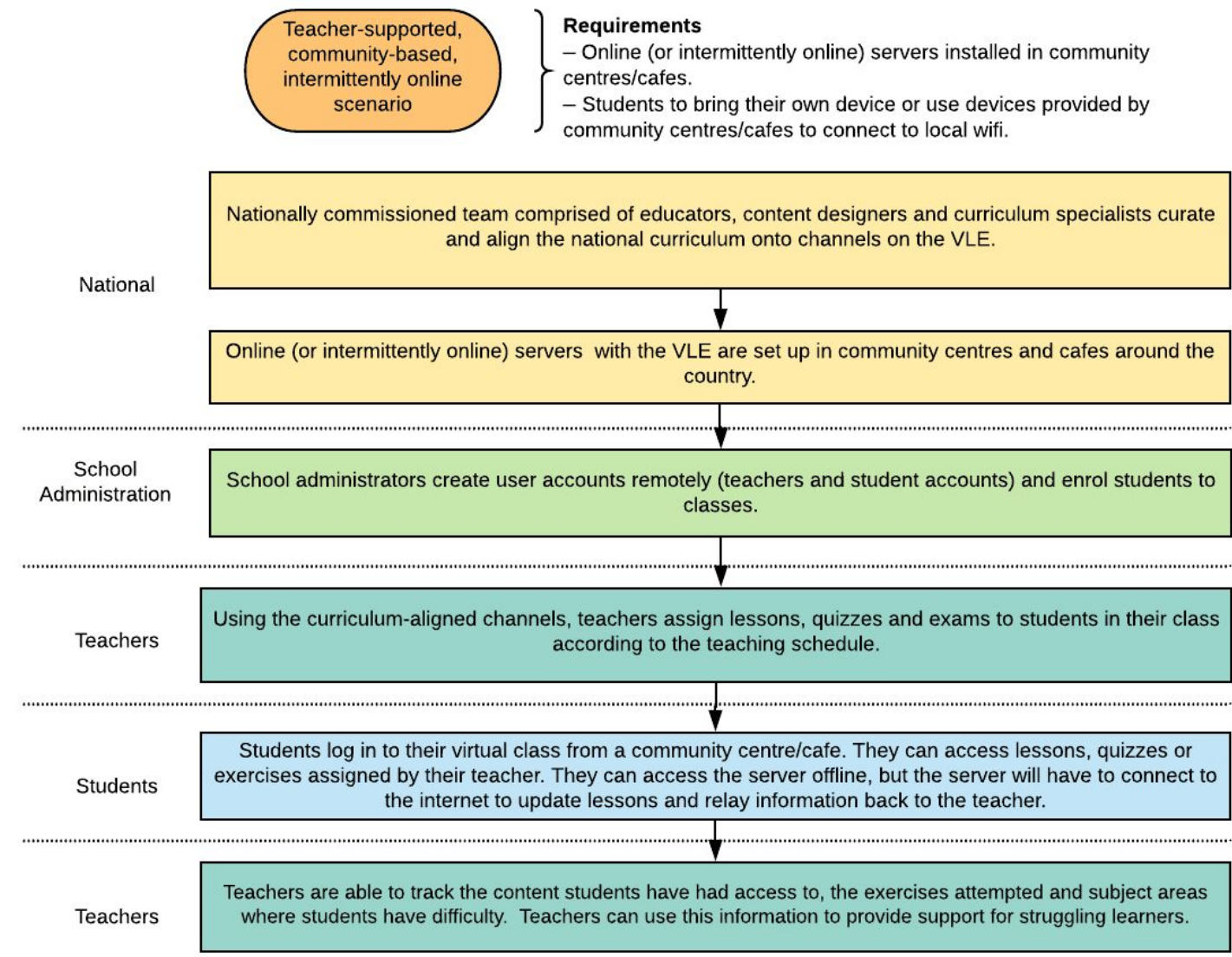

Figure 7. teacher-supported, community-based, partially online configuration

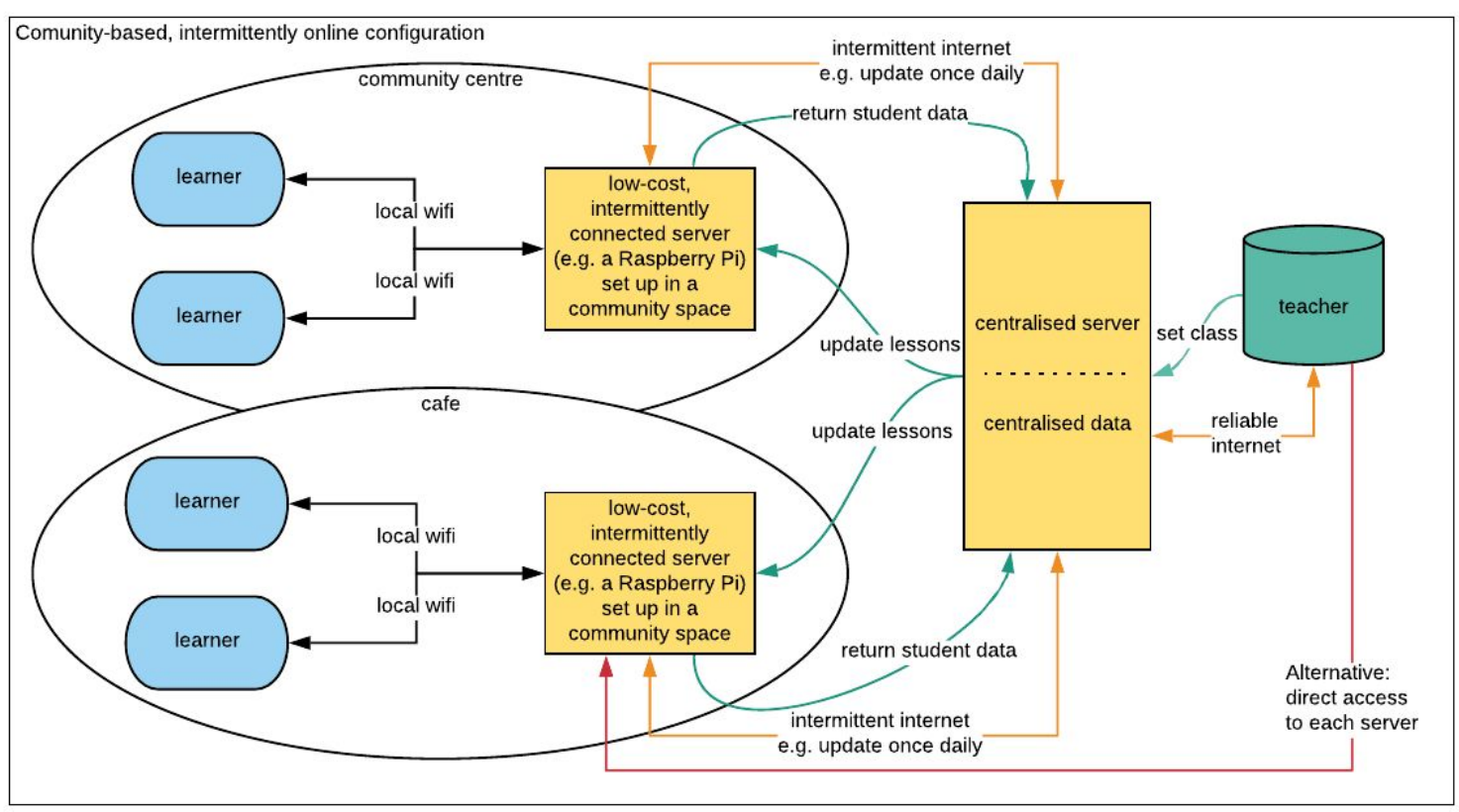




\subsubsection{Teacher-supported, out-of-school, fully online scenario}

In a fully online VLE, there is no need to go to a community centre or cafe. This is the conventional VLE scenario. Teachers and students can access the VLE online from anywhere if they have access to the internet. Teachers can share content and exercises with learners, as well as to assess students and track their progress. In a fully online scenario, it is also possible to incorporate synchronous virtual classes if everyone has access to the internet at the same time. This configuration should be used cautiously as it limits access to underprivileged students.

Figure 8 (below) outlines the process of how a teacher supported, out-of-school, online scenario would work, and Figure 9 (below) outlines the configuration of a teacher-supported, out-of-school, online scenario.

In this configuration, teachers and students do not need to be in any particular location. As they are using the internet, they can access the VLE from anywhere. 
Figure 8. Process for teacher supported, out-of-school, online scenario

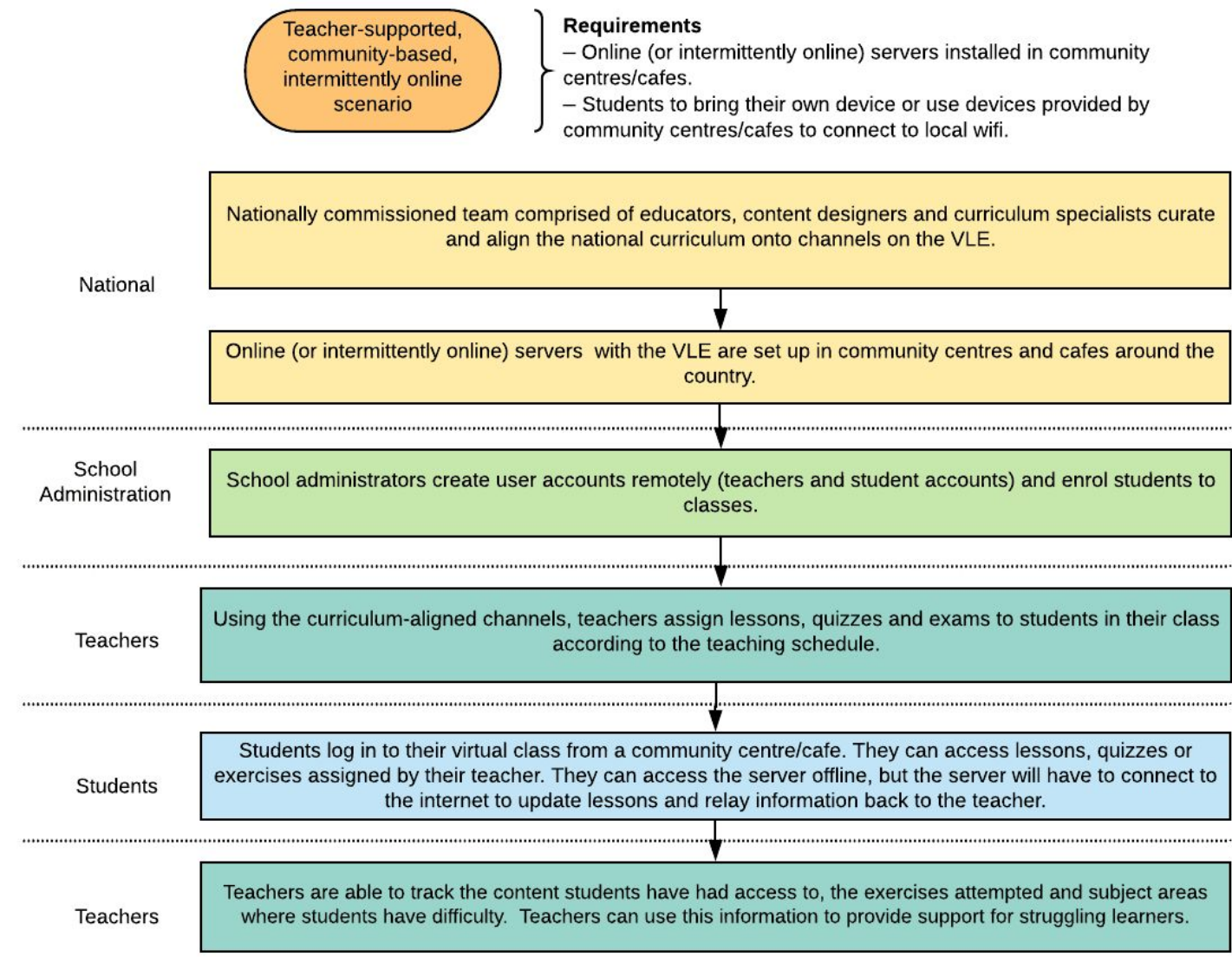

Figure 9. Teacher-supported, out-of-school, online configuration

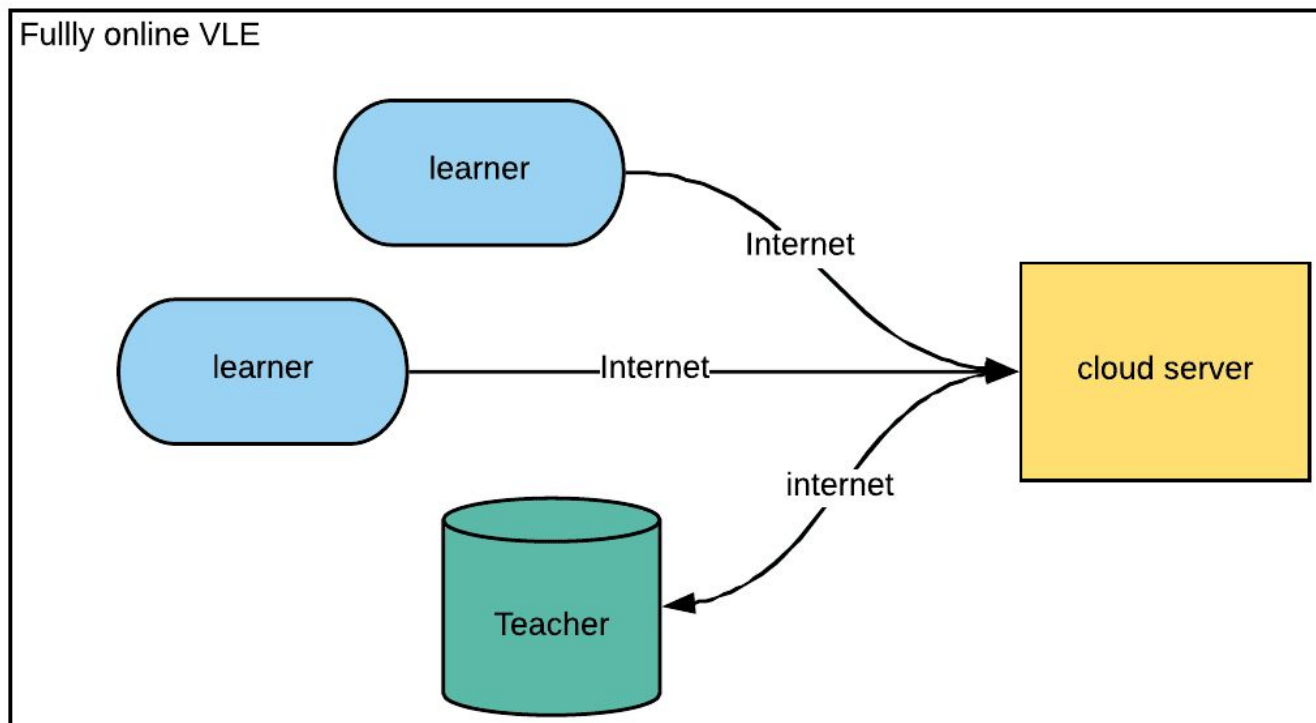




\section{An agille approach to setting up a national VLE}

In a traditional 'waterfall' development approach, the end goal is set at the beginning of the process. You develop a product or service to that predefined end goal, without ever questioning whether that end goal remains desirable. Moreover, the process focuses on building components - such as the parts of a car — with the final, fully-functional product only being available right at the end of the process (Figure 10). In agile development, an iterative, flexible and adaptable approach is taken. Rather than building the parts of the whole (for later assembly), agile development creates a sequence of 'minimal viable products'. A minimal viable product is the most basic version of the product needed to provide feedback for further development. It helps to assess and evaluate whether the product is developing in the right direction, towards a product that will be as useful and impactful as possible. Figure 10 illustrates the difference between 'waterfall' development and agile development. In a 'waterfall' approach, various components are made, but the first functional product is only available in the final stage. The agile model seeks to create a minimal viable product in each iteration: Suppose you need to get from A to B - what product do you need? You might assume that you need a car, and so you build one. However, you may find that the car just gets stuck in traffic. If you iterate from the simplest mode of transport, towards more elaborate ones, you may learn important things along the way.

Figure 10. Agile development vs traditional development approaches


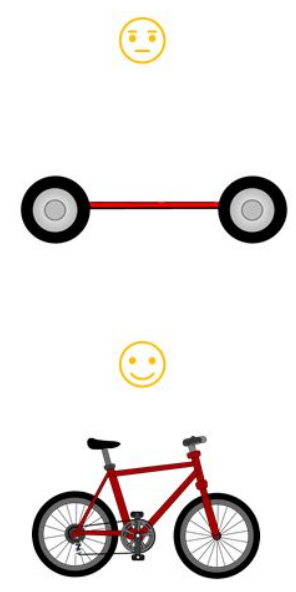

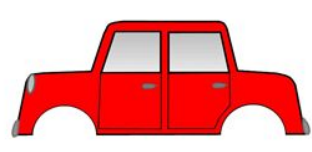
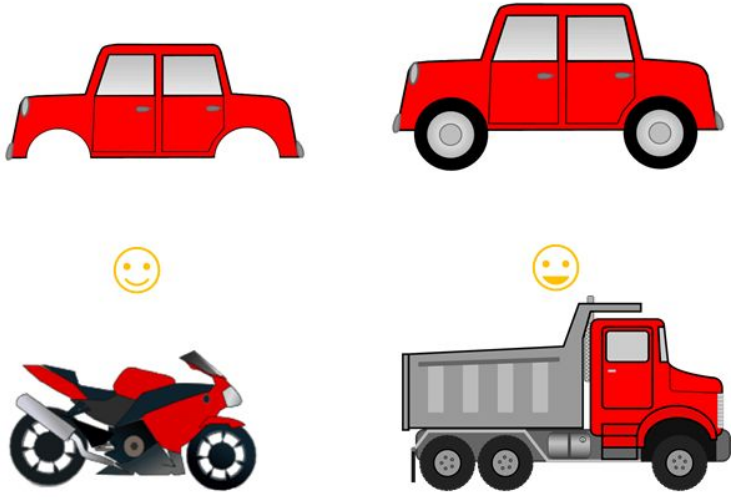

In agile development, different, subsequent phases of the development of a product or service are sometimes labeled as 'discovery', 'alpha', 'beta' and 'live'. In this document, we use the guidelines from the UK Government Digital Service ${ }^{6}$, which defines those phases as follows:

6. Discovery. The discovery phase is where the problem is fully unpacked, defined and investigated. This phase investigates the different users and their contexts, the constraints, and the possible opportunities. Problem-Driven Iterative Adaptation $^{7}$ overlaps with this phase and is integrated here.

${ }^{6}$ https://www.gov.uk/service-manual/agile-delivery

${ }^{7}$ https://bsc.cid.harvard.edu/files/bsc/files/pdiatoolkit ver 1 oct 2018.pdf 
7. Alpha. The alpha phase is where multiple small prototypes which aim to address the problem are designed and implemented.

8. Beta. The beta phase is where the best idea from the alpha phase is developed further and tested at a larger scale.

9. Live. The live phase is when the product or service is supported in a sustainable way at full scale, while continuing to iteratively improve it.

The agile development process emphasises a strong discovery phase where the problem and its assumptions are thoroughly investigated. Further, it emphasises reflection and redesign after each design phase. Figure $11^{8}$ illustrates this process.

Figure 11. Agile development process

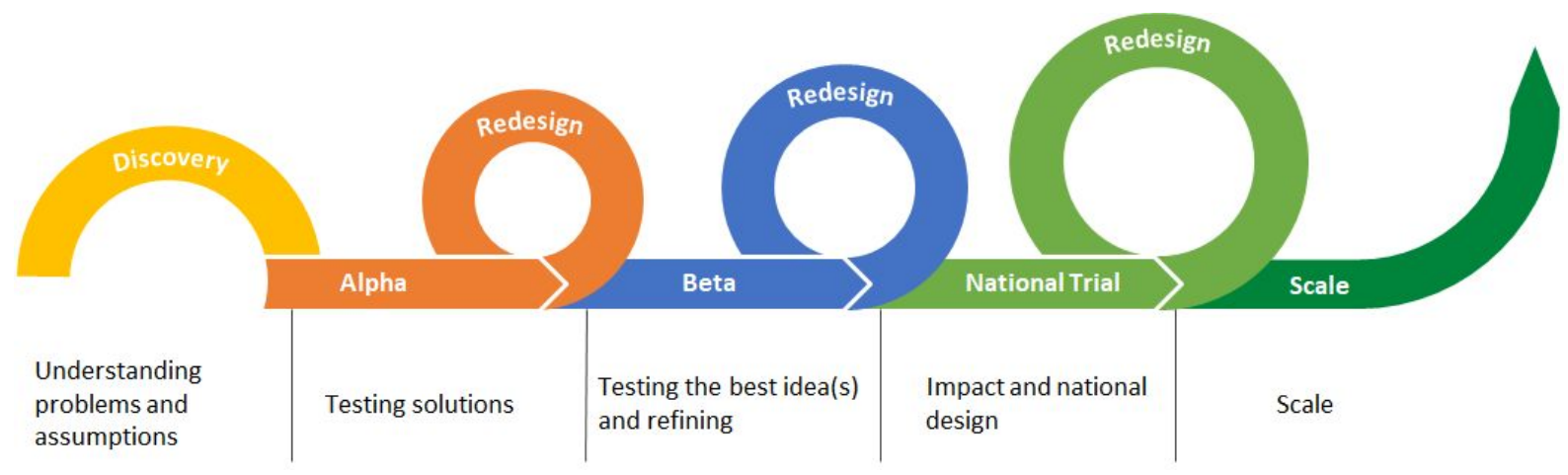

Figure 12 (below) outlines a sequence of steps, based on an agile approach, that implementers should take when considering setting up a national VLE.

\footnotetext{
${ }^{8}$ This figure was developed as part of the Activating Edtech programme in Jordan, a project that aims to introduce agile development practices to educational technology policymaking ( $\Uparrow$ Khalayleh, 2020). More information can be found here:

https://opendeved.net/2020/04/03/arabic-version-of-design-thinking-for-educators/.
} 


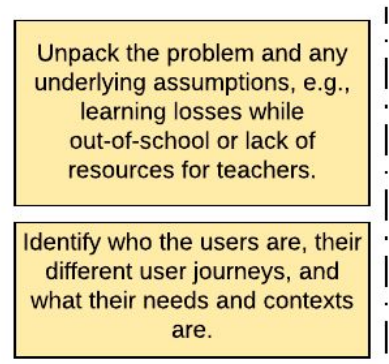

Explore what types of VLEs exist and what kind of VLE set-up, if any, would best address the problem.

Investigate whether national and school infrastructure is ready for a national VLE.

Investigate how much nationally-aligned digitised content exists and how much time and resources it would take to fully prepare content for the VLE.

Discovering the
learning needs of
students

Discovery

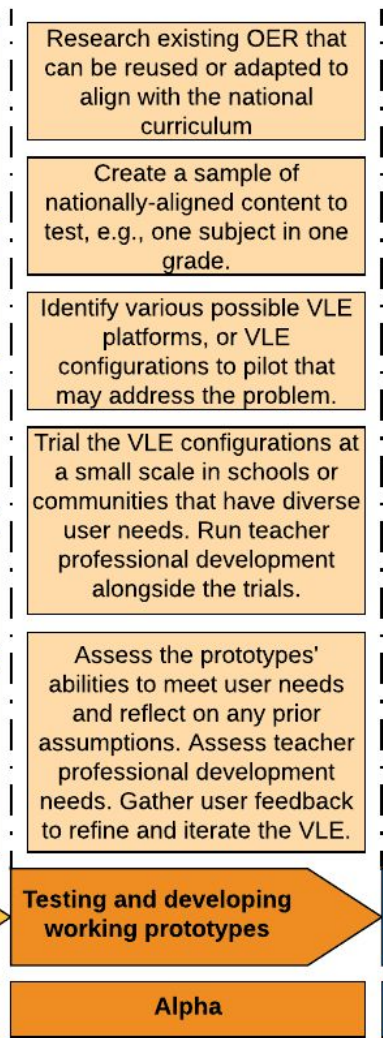

1

Source and align content for a wider range of subjects and grade levels in your chosen VLE.

Trial your VLE with 100 schools or communities in varying contexts, e.g., in rural contexts or areas with no electricity/internet. Consider how the VLE supports specia needs children.

Continue to run teacher pontinue to run teacher
professional development to support teachers in using the VLE. Assess how this can be improved.

Check the capacity of your VLE and if it meets the needs of real users. Identify unexpected practical constraints.

1

Iterate your VLE to ensure the product works as well as possible in your specific context.

\section{Testing and developing}

your product/service at a larger scale

\section{Beta}

Fully populate the VLE with learning content (including exercises and quizzes) for all target users, according to grade and subject.

Trial VLE at a national scale, opening your it up publically to all those who need it.

Expand the teacher professional development programme nationally.

Monitor the capacity of your VLE to address evolving user needs.

Continually iterate and refine the VLE to meet new demands.

Using your product/service at a national scale

Live

These steps will be unpacked in further detail throughout this document. 


\section{Discovery}

The discovery phase focuses on unpacking the problem, its assumptions and the context within which the problems occur. In order to benefit from Discovery, it is advisable to use one of the available toolkits. We highly encourage using the Problem-Driven Iterative Adaptation toolkit ${ }^{9}$ or $\uparrow$ Design Thinking for Educators process (Schurr, 2013) to fully explore and understand the problems that need to be addressed.

Problem-Driven, Iterative Adaptation is a learning-by-doing approach. The toolkit is a step-by-step approach which helps to break problems down into their root causes, identify entry points to begin addressing the problem, search for possible services or products that can address the problem, take action, reflect upon what has been learnt, adapt responses and then act again. It is a dynamic process with tight feedback loops that allows you to build responses to your problem that fits your local context.

In this document, the discovery phase is divided into five sections related to setting up a national VLE:

1. Investigating the problem and defining the possible role of a VLE:

2. Investigating infrastructure readiness;

3. Investigating educator readiness;

4. Investigating student readiness:

5. Investigating content readiness.

The following subsections unpack these themes, outlining considerations that need to be made before embarking on setting up a national VLE.

\subsection{Investigating the actual problem and whether a VLE can help solve it}

This section provides sets of questions to help unpack the problem and ascertain whether a VLE can contribute to addressing this problem. Additionally, the questions help to ascertain what type of VLE best addresses the problem and the context. The questions in Table 1 are not exhaustive but serve as a starting point to stimulate the discovery process.

\footnotetext{
${ }^{9}$ https://bsc.cid.harvard.edu/files/bsc/files/pdiatoolkit ver 1 oct 2018.pdf
} 
Table 1. Discovery. Defining the problem and the role of a VLE platform

\begin{tabular}{|c|c|}
\hline \multicolumn{2}{|c|}{ Discovery. Defining the problem and the role of a VLE platform } \\
\hline Questions & Further questions \\
\hline \multirow{5}{*}{$\begin{array}{l}\text { What is the problem } \\
\text { being addressed? }\end{array}$} & What was the state of learning prior to the pandemic? \\
\hline & How has COVID-19 affected learning? \\
\hline & $\begin{array}{l}\text { Is the problem lack of out-of-school learning support and } \\
\text { resources? }\end{array}$ \\
\hline & $\begin{array}{l}\text { Is the problem that teachers lack access to teaching and learning } \\
\text { materials? }\end{array}$ \\
\hline & $\begin{array}{l}\text { Is the problem that children lack access to school feeding } \\
\text { schemes? }\end{array}$ \\
\hline \multirow{5}{*}{$\begin{array}{l}\text { Is a VLE the best way of } \\
\text { addressing the problem? }\end{array}$} & How does a VLE address the problems identified? \\
\hline & What are the other alternatives to VLEs? \\
\hline & How do alternative interventions address the problems identified? \\
\hline & $\begin{array}{l}\text { What are the risks and unintended consequences of implementing } \\
\text { a VLE or other alternatives? }\end{array}$ \\
\hline & What type of VLE could best address the problems identified? \\
\hline \multirow{5}{*}{$\begin{array}{l}\text { Should you build your } \\
\text { own VLE platform or use a } \\
\text { pre-existing platform? }\end{array}$} & Is there already some form of a VLE in place? \\
\hline & If so, what types of VLEs are in place? \\
\hline & What needs do these VLEs not meet? \\
\hline & $\begin{array}{l}\text { Are there unique needs that cannot be addressed by existing VLE } \\
\text { platforms available? }\end{array}$ \\
\hline & $\begin{array}{l}\text { Do you have the knowledge, financial resources and technical } \\
\text { expertise to build a new VLE? }\end{array}$ \\
\hline \multirow{4}{*}{$\begin{array}{l}\text { Who will be the users of } \\
\text { the VLE? }\end{array}$} & Are teachers or students the primary users of the platform? \\
\hline & How old are the students who will be using the platform? \\
\hline & $\begin{array}{l}\text { Will students, particularly younger students, need parental } \\
\text { support? }\end{array}$ \\
\hline & $\begin{array}{l}\text { How will teachers, students and parents each respectively use the } \\
\text { VLE platform? }\end{array}$ \\
\hline
\end{tabular}




\subsubsection{What is the problem being addressed?}

Before embarking on setting up a VLE, the problem and underlying assumptions need to be explored. While education planners are considering VLEs due to the COVID-19 pandemic that has led to the need for out-of-school learning, the quality of the education system before the pandemic also needs to be considered. In many low- and middle-income countries there has been a learning crisis, meaning that although children are attending school, they are not necessarily learning at school. If the existing education system was not functioning well in the first place, it could mean that the pandemic has exacerbated an already bad situation (Haßler, 2020). To address a pre-existing learning crisis, investments to improve learning outcomes may be better placed in teacher professional development than in rolling out a VLE.

During the pandemic, the main impact of children being out of school may be lack of access to school feeding schemes or place of shelter and support outside of home. Again, these problems would not be addressed by implementing a VLE.

\subsubsection{Is a VLE the best way of addressing the problem?}

For out-of-school use, implementers need to examine which populations can actually use a VLE. In many low- and middle-income countries, marginalised communities will not have immediate access to VLEs due to poor connectivity or lack of devices. Implementers should consider alternative modes of delivery such as radio, television, non-smartphone and print media to reach disadvantaged populations, particularly during the current pandemic (îHaßler, et al., 2020).

Implementers should give preference to VLEs that can function on basic smartphones and non-smart phones, i.e., the VLE should be mobile-compatible for different screen sizes and backward-compatible across various browsers. Moreover, implementers should explore the option of zero-rating online learning resources to remove the barrier of data costs (^McBurnie, et al., 2020).

If education providers do not already have a VLE in operation or nationally-aligned digital content prepared, we strongly advise against rolling out a new platform in a rush. Instead, implementers should take time to properly unpack and define the problem that needs to be addressed. Utilising the process outlined in this note, implementers can - over the next 12 to 18 months - establish a well-thought-out VLE.

For any internet-based intervention, implementers need to examine the associated risks. Online learning can put children at a greater risk of cyberbullying, sexual exploitation, loss of personal data and exposure to harmful content ( 1 UNICEF, et al., 2020). Moreover, the development of a VLE can take time and resources away from other interventions.

\subsubsection{Should you build your own VLE or use a pre-existing VLE platform?}

Unless the context or user needs differ drastically from existing VLE models, programme implementers should adapt existing VLE platforms to their needs rather than building their own platforms from scratch. Current VLE platform options already offer a number of features that can support learning in a wide variety of contexts (see 
$\hat{\wedge}$ McBurnie (2020)). Using existing VLE platforms to reduce the time and cost of software development. Many of these VLE platforms allow implementers to use readily available curriculum-aligned materials, incorporate supplementary resources and upload their own content.

\subsubsection{Who will be the users of the VLE?}

Depending on the exact purpose of the VLE, it will need to be designed differently for different types of users. Additionally, it will need to have the functionality to support various different users. Table 2 outlines questions for each of the possible user groups of the VLE.

Table 2. Discovery. Users of the VLE

\begin{tabular}{|c|c|c|}
\hline \multicolumn{3}{|c|}{ Discovery. Users of the VLE } \\
\hline Questions & \multicolumn{2}{|l|}{ Further Questions } \\
\hline \multirow{5}{*}{$\begin{array}{l}\text { Who are the } \\
\text { main users } \\
\text { of the } \\
\text { platform? }\end{array}$} & Teachers & $\square$ \\
\hline & Upper secondary school learners & $\square$ \\
\hline & Lower secondary school learners & $\square$ \\
\hline & Primary school learners & $\square$ \\
\hline & Parents & $\square$ \\
\hline \multirow{5}{*}{ Teachers } & \multicolumn{2}{|l|}{ What needs do teachers have? } \\
\hline & \multicolumn{2}{|l|}{ Why do they have these needs? } \\
\hline & \multicolumn{2}{|l|}{ Is the VLE designed for primary use by a teacher? } \\
\hline & \multicolumn{2}{|l|}{$\begin{array}{l}\text { Is the VLE meant to be a teacher support tool to access curriculum-aligned } \\
\text { content? }\end{array}$} \\
\hline & \multicolumn{2}{|l|}{$\begin{array}{l}\text { How will teachers make use of the VLE in a school-based setting and in an } \\
\text { out-of-school setting? }\end{array}$} \\
\hline \multirow{5}{*}{ Students } & \multicolumn{2}{|l|}{ What needs do students have? } \\
\hline & \multicolumn{2}{|l|}{ Why do they have these needs? } \\
\hline & \multicolumn{2}{|l|}{ Are students going to be accessing the VLE directly? } \\
\hline & \multicolumn{2}{|l|}{ How old are the students? } \\
\hline & \multicolumn{2}{|l|}{$\begin{array}{l}\text { Are students going to be accessing the VLE indirectly through parents or } \\
\text { teachers? }\end{array}$} \\
\hline \multirow{4}{*}{ Parents } & \multicolumn{2}{|l|}{ What needs do parents have? } \\
\hline & \multicolumn{2}{|l|}{ Why do they have these needs? } \\
\hline & \multicolumn{2}{|l|}{ Are parents actually the main users of the platform for younger students? } \\
\hline & \multicolumn{2}{|l|}{ What level of support is needed from parents? } \\
\hline
\end{tabular}


Understanding each user's needs is key to ensuring the VLE is implemented correctly.

\section{Teachers}

In resource-constrained areas, it may be better to design the VLE for use by teachers as it is unlikely that learners will have access to devices. In this scenario, the aim here might be to provide under-trained teachers with access to teaching and learning resources. Teachers can use the curriculum-aligned content to improve their own knowledge on the subject matter and incorporate it into their classroom teaching. In this case, the VLE would serve as a tool for teacher professional development rather than a system to support out-of-school learning.

\section{Students}

If students are going to be directly accessing the VLE, it needs to be designed in a child-friendly way, with particular focus on a simple but engaging user interface. Depending on the age of the learners, they may need varying levels of support from parents, teachers or community members. Pre-primary and primary school students may need constant support both technologically and pedagogically. Older students may need less support, but in general, all students will always need to have a support system nearby. If the student is accessing the internet, there are also other safety concerns which the guardian or teacher needs to look out for.

\section{Parents}

In an out-of-school scenario, parents play a pivotal role in supporting their child's learning. Parents, however, are not school teachers and cannot be treated as such. Many of them might not have had the opportunity to further their own education. Additionally, a high level of digital literacy cannot be expected from parents. It is likely that parents or guardians will be the ones supporting their children in accessing a VLE at home or in a community centre. Thus, teachers and school administrators need to communicate clearly with parents on what they need to do or what is needed from them.

\subsubsection{Discuss your findings}

Based on all the above questions, discuss your findings. Does rolling out a VLE truly address the educational needs of students? If the country was already facing a learning crisis prior to the COVID-19 pandemic, is funding better spent first addressing these underlying issues? Perhaps a VLE that is targeted at supporting teachers, rather than learners, might have a larger impact?

We recommend conducting user research or bringing together multiple stakeholders to unpack these questions together. It is important to listen to the needs of teachers, parents and students, to properly understand the problem. If their needs are not met in the intervention, a lot of time and investment will be wasted.

As a reminder, for a more extensive examination of the issues, you should use toolkits like the Problem-Driven Iterative Adaptation toolkit or Design Thinking for Educators process. 
While this section prompts more open-ended and exploratory questions to unpack the problem, the following sections take a more structured approach to investigate the readiness for a national VLE implementation.

\subsection{Infrastructure readiness}

This section evaluates the readiness of national infrastructure. It extends the evaluation outlined in our five-part education response to the COVID-19 pandemic, which we also recommend (․ Haßler, et al., 2020). The questionnaire in Table 3 is broken down according to different sub-populations or geographic groups as access often varies according to these factors. Both national infrastructure and school infrastructure are covered. Tick or fill in the boxes that apply.

Table 3. Discovery. Infrastructure Readiness

\begin{tabular}{|c|c|c|c|c|c|c|}
\hline \multicolumn{7}{|c|}{ Discovery. Infrastructure Readiness } \\
\hline Questions & & & Fill in & & & \\
\hline \multirow{6}{*}{$\begin{array}{l}\text { What percentage } \\
\text { of the population } \\
\text { sub-groups has } \\
\text { access to the } \\
\text { internet? }\end{array}$} & Percentage & $\begin{array}{l}\text { High } \\
\text { income }\end{array}$ & $\begin{array}{l}\text { Low } \\
\text { income }\end{array}$ & Men & Women & Average \\
\hline & $0 \%-20 \%$ & $\square$ & $\square$ & $\square$ & $\square$ & $\square$ \\
\hline & $20 \%-40 \%$ & $\square$ & $\square$ & $\square$ & $\square$ & $\square$ \\
\hline & $40 \%-60 \%$ & $\square$ & $\square$ & $\square$ & $\square$ & $\square$ \\
\hline & $60 \%-80 \%$ & $\square$ & $\square$ & $\square$ & $\square$ & $\square$ \\
\hline & $80 \%-100 \%$ & $\square$ & $\square$ & $\square$ & $\square$ & $\square$ \\
\hline \multirow{6}{*}{$\begin{array}{l}\text { What is the } \\
\text { percentage of } \\
\text { internet coverage } \\
\text { in various parts of } \\
\text { the country? }\end{array}$} & Percentage & Urban & Peri-urban & Rural & & Average \\
\hline & $0 \%-20 \%$ & $\square$ & $\square$ & $\square$ & & $\square$ \\
\hline & $20 \%-40 \%$ & $\square$ & $\square$ & $\square$ & & $\square$ \\
\hline & $40 \%-60 \%$ & $\square$ & $\square$ & $\square$ & & $\square$ \\
\hline & $60 \%-80 \%$ & $\square$ & $\square$ & $\square$ & & $\square$ \\
\hline & $80 \%-100 \%$ & $\square$ & $\square$ & $\square$ & & $\square$ \\
\hline \multirow{7}{*}{$\begin{array}{l}\text { What are the } \\
\text { bandwidth } \\
\text { limitations in } \\
\text { different areas of } \\
\text { the country? }\end{array}$} & Bandwidth & Urban & Peri-urban & Rural & & Average \\
\hline & $<1 \mathrm{Mbps}$ & $\square$ & $\square$ & $\square$ & & $\square$ \\
\hline & $5 \mathrm{Mbps}$ & $\square$ & $\square$ & $\square$ & & $\square$ \\
\hline & $25 \mathrm{Mbps}$ & $\square$ & $\square$ & $\square$ & & $\square$ \\
\hline & $50 \mathrm{Mbps}$ & $\square$ & $\square$ & $\square$ & & $\square$ \\
\hline & $100 \mathrm{Mbps}$ & $\square$ & $\square$ & $\square$ & & $\square$ \\
\hline & > $100 \mathrm{Mbps}$ & $\square$ & $\square$ & $\square$ & & $\square$ \\
\hline \multirow{2}{*}{$\begin{array}{l}\text { What is the mobile } \\
\text { cost of data per }\end{array}$} & Cost/GB & ISP 1 & ISP 2 & ISP 3 & ISP 4 & Average \\
\hline & $<\$ 1$ & $\square$ & $\square$ & $\square$ & $\square$ & $\square$ \\
\hline
\end{tabular}




\begin{tabular}{|c|c|c|c|c|c|c|}
\hline \multirow{5}{*}{$\begin{array}{l}\text { GB from different } \\
\text { Internet Service } \\
\text { Providers (ISPs)? }\end{array}$} & $\$ 1-\$ 2$ & $\square$ & $\square$ & $\square$ & $\square$ & $\square$ \\
\hline & $\$ 2-\$ 5$ & $\square$ & $\square$ & $\square$ & $\square$ & $\square$ \\
\hline & $\$ 5-\$ 10$ & $\square$ & $\square$ & $\square$ & $\square$ & $\square$ \\
\hline & $\$ 10-\$ 20$ & $\square$ & $\square$ & $\square$ & $\square$ & $\square$ \\
\hline & $>\$ 20$ & $\square$ & $\square$ & $\square$ & $\square$ & $\square$ \\
\hline \multirow{3}{*}{$\begin{array}{l}\text { Are various parties } \\
\text { planning to invest } \\
\text { in further network } \\
\text { infrastructure? }\end{array}$} & & ISP 1 & ISP 2 & ISP 3 & Government & Average \\
\hline & Yes & $\square$ & $\square$ & $\square$ & $\square$ & $\square$ \\
\hline & No & $\square$ & $\square$ & $\square$ & $\square$ & $\square$ \\
\hline \multirow{6}{*}{$\begin{array}{l}\text { What percentage } \\
\text { of schools have } \\
\text { adequate } \\
\text { infrastructure (e.g. } \\
\text { desks, chairs, } \\
\text { textbooks, water, } \\
\text { toilets)? }\end{array}$} & Percentage & Urban & Rural & Public & Private & Average \\
\hline & $0 \%-20 \%$ & $\square$ & $\square$ & $\square$ & $\square$ & $\square$ \\
\hline & $20 \%-40 \%$ & $\square$ & $\square$ & $\square$ & $\square$ & $\square$ \\
\hline & $40 \%-60 \%$ & $\square$ & $\square$ & $\square$ & $\square$ & $\square$ \\
\hline & $60 \%-80 \%$ & $\square$ & $\square$ & $\square$ & $\square$ & $\square$ \\
\hline & $80 \%-100 \%$ & $\square$ & $\square$ & $\square$ & $\square$ & $\square$ \\
\hline \multirow{6}{*}{$\begin{array}{l}\text { What percentage } \\
\text { of schools have } \\
\text { electricity? }\end{array}$} & Percentage & Urban & Rural & Public & Private & Average \\
\hline & $0 \%-20 \%$ & $\square$ & $\square$ & $\square$ & $\square$ & $\square$ \\
\hline & $20 \%-40 \%$ & $\square$ & $\square$ & $\square$ & $\square$ & $\square$ \\
\hline & $40 \%-60 \%$ & $\square$ & $\square$ & $\square$ & $\square$ & $\square$ \\
\hline & $60 \%-80 \%$ & $\square$ & $\square$ & $\square$ & $\square$ & $\square$ \\
\hline & $80 \%-100 \%$ & $\square$ & $\square$ & $\square$ & $\square$ & $\square$ \\
\hline \multirow{6}{*}{$\begin{array}{l}\text { What percentage } \\
\text { of schools have } \\
\text { access to the } \\
\text { internet? }\end{array}$} & Percentage & Urban & Rural & Public & Private & Average \\
\hline & $0 \%-20 \%$ & $\square$ & $\square$ & $\square$ & $\square$ & $\square$ \\
\hline & $20 \%-40 \%$ & $\square$ & $\square$ & $\square$ & $\square$ & $\square$ \\
\hline & $40 \%-60 \%$ & $\square$ & $\square$ & $\square$ & $\square$ & $\square$ \\
\hline & $60 \%-80 \%$ & $\square$ & $\square$ & $\square$ & $\square$ & $\square$ \\
\hline & $80 \%-100 \%$ & $\square$ & $\square$ & $\square$ & $\square$ & $\square$ \\
\hline
\end{tabular}

If population sub-groups have little access to the internet or live in regions of low internet coverage, this indicates that a fully online VLE model would not be able to reach them. If bandwidth is limited, this means that low-data-intensive content needs to be designed. Regarding the cost of data, ${ }^{10}$ if this is too high, particularly in comparison to the minimum wage in the country, a VLE that depends on internet access will not be accessible. In this case, zero-rating the VLE may assist in increasing access (see iMcBurnie, et al., 2020).

${ }^{10}$ For further information on data costs around the world, last updated in February 2020, see https://www.cable.co.uk/mobiles/worldwide-data-pricing/. 
If a decent level of classroom infrastructure and amenities are not in place in schools, investments should first be made towards addressing these basic necessities before investing in a VLE. If the school does not have access to electricity, neither an offline or online VLE will work. If there is electricity, but no internet access, an offline VLE might work. As the school is a key gathering point in a community, it is likely that its conditions reflect those of the students in the community. Thus, if the school does not have internet access, it is unlikely that students will. 


\subsection{Teacher readiness}

The following questions in Table 4 help to evaluate whether teachers are ready to teach using a VLE. Additionally, it ascertains whether sufficient support mechanisms will be put in place to help teachers develop skills in distance and online learning pedagogies.

Table 4. Discovery. Teacher Readiness

\begin{tabular}{|c|c|c|c|}
\hline \multicolumn{4}{|c|}{ Discovery. Educator Readiness } \\
\hline \multirow[b]{2}{*}{ Questions } & \multirow[b]{2}{*}{ Options } & \multicolumn{2}{|c|}{ Tick/Fill in } \\
\hline & & Public & Private \\
\hline \multirow{7}{*}{$\begin{array}{l}\text { What are the main issues } \\
\text { with regard to teachers' } \\
\text { ability to support } \\
\text { learners? }\end{array}$} & Underqualified teachers & $\square$ & $\square$ \\
\hline & Underpaid teachers & $\square$ & $\square$ \\
\hline & $\begin{array}{l}\text { Lack of continuous teacher professional } \\
\text { development for teachers }\end{array}$ & $\square$ & $\square$ \\
\hline & Lack of quality teachers in rural and remote areas & $\square$ & $\square$ \\
\hline & Teacher absenteeism & $\square$ & $\square$ \\
\hline & Overworked teachers & $\square$ & $\square$ \\
\hline & Other & $\square$ & $\square$ \\
\hline \multirow{8}{*}{$\begin{array}{l}\text { What percentage of } \\
\text { teachers have access to } \\
\text { the listed devices? }\end{array}$} & No devices & $\%$ & $\%$ \\
\hline & Radio & $\%$ & $\%$ \\
\hline & Television & $\%$ & $\%$ \\
\hline & Feature phone & $\%$ & $\%$ \\
\hline & Smartphone & $\%$ & $\%$ \\
\hline & MP3 player & $\%$ & $\%$ \\
\hline & Tablet & $\%$ & $\%$ \\
\hline & Laptop & $\%$ & $\%$ \\
\hline \multirow{7}{*}{$\begin{array}{l}\text { What percentage of } \\
\text { teachers have digital or } \\
\text { internet literacy in the } \\
\text { listed categories? }\end{array}$} & Mobile phone. Able to comfortably: & & \\
\hline & navigate a feature phone & $\%$ & $\%$ \\
\hline & navigate a smartphone & $\%$ & $\%$ \\
\hline & use messaging applications & $\%$ & $\%$ \\
\hline & use email on mobile phone & $\%$ & $\%$ \\
\hline & browse the internet & $\%$ & $\%$ \\
\hline & decipher useful information from spam, & $\%$ & $\%$ \\
\hline
\end{tabular}




\begin{tabular}{|c|c|c|c|}
\hline & advertisements and misinformation & & \\
\hline & Laptop / Desktop. Able to comfortably: & & \\
\hline & use a keyboard and mouse & $\%$ & $\%$ \\
\hline & use word processor and spreadsheets & $\%$ & $\%$ \\
\hline & browse the internet & $\%$ & $\%$ \\
\hline & use email on laptop / desktop & $\%$ & $\%$ \\
\hline & $\begin{array}{l}\text { distinguish useful information from spam, } \\
\text { advertisements and misinformation }\end{array}$ & $\%$ & $\%$ \\
\hline & no digital or internet literacy & $\%$ & $\%$ \\
\hline & Completed pre-service training & $\square$ & $\square$ \\
\hline What amount of teacher & Completed in-service training & $\square$ & $\square$ \\
\hline $\begin{array}{l}\text { professional development } \\
\text { have teachers had } \\
\text { generally? }\end{array}$ & $\begin{array}{l}\text { Attend infrequent teacher professional } \\
\text { development workshops (e.g., every few years) }\end{array}$ & $\square$ & $\square$ \\
\hline & $\begin{array}{l}\text { Receive continuous teacher professional } \\
\text { development }\end{array}$ & $\square$ & $\square$ \\
\hline & None & $\square$ & $\square$ \\
\hline What amount of teacher & Some emergency training during the pandemic & $\square$ & $\square$ \\
\hline $\begin{array}{l}\text { have teachers received in } \\
\text { distance and online }\end{array}$ & $\begin{array}{l}\text { Some edtech-integrated teacher professional } \\
\text { development }\end{array}$ & $\square$ & $\square$ \\
\hline pedagogies? & $\begin{array}{l}\text { Advanced edtech-integrated teacher professional } \\
\text { development }\end{array}$ & $\square$ & $\square$ \\
\hline & None & $\square$ & $\square$ \\
\hline What amount of teacher & Some emergency training during the pandemic & $\square$ & $\square$ \\
\hline $\begin{array}{l}\text { have teachers received in } \\
\text { digital content }\end{array}$ & $\begin{array}{l}\text { Some teacher professional development in } \\
\text { content design }\end{array}$ & $\square$ & $\square$ \\
\hline development? & $\begin{array}{l}\text { Advanced teacher professional development in } \\
\text { content design }\end{array}$ & $\square$ & $\square$ \\
\hline When does the ministry of & No plan & $\square$ & $\square$ \\
\hline nationally support teacher & In the next 6 months & $\square$ & $\square$ \\
\hline professional development & Within the next two years & $\square$ & $\square$ \\
\hline learning? & We have already implemented a national plan & $\square$ & $\square$ \\
\hline $\begin{array}{l}\text { In what ways does the } \\
\text { ministry of education plan }\end{array}$ & $\begin{array}{l}\text { We will distribute printed materials on distance } \\
\text { and online pedagogies }\end{array}$ & $\square$ & $\square$ \\
\hline teachers for pedagogical & We will run online courses to train teachers in & $\square$ & $\square$ \\
\hline
\end{tabular}




\begin{tabular}{|c|c|c|c|}
\hline \multirow{4}{*}{$\begin{array}{l}\text { readiness in distance and } \\
\text { online learning? }\end{array}$} & distance and online pedagogies & & \\
\hline & $\begin{array}{l}\text { We will ensure every teacher attends a } \\
\text { face-to-face workshop on distance and online } \\
\text { pedagogies. }\end{array}$ & $\square$ & $\square$ \\
\hline & $\begin{array}{l}\text { We will use the VLE to support teacher } \\
\text { professional development }\end{array}$ & $\square$ & $\square$ \\
\hline & $\begin{array}{l}\text { We will use a cascade model whereby we train } \\
\text { selected teachers in each school so they can } \\
\text { in-turn train the rest of the teachers }\end{array}$ & $\square$ & $\square$ \\
\hline \multirow{3}{*}{$\begin{array}{l}\text { Does the ministry of } \\
\text { education have facilitators } \\
\text { or coaches to support } \\
\text { teachers? }\end{array}$} & Yes & $\square$ & $\square$ \\
\hline & No & $\square$ & $\square$ \\
\hline & We will procure them & $\square$ & $\square$ \\
\hline
\end{tabular}

The questions in Table 4 (above) will help you to ascertain current issues affecting teachers' ability to effectively support learners as these issues are likely to be amplified in a VLE. Investigating teachers' access to devices helps to determine whether teachers would be able to access the VLE in an out-of-school scenario. Additionally, teachers' digital and internet literacy is key to them being able to utilise a VLE. For teachers, however, digital and internet literacy is not enough as they need teacher professional development in distance and online pedagogies. Even if teachers have had teacher professional development for traditional in-person teaching, teaching at a distance or online requires new skills. It is important that teachers develop these new skills before or in conjunction with the roll-out of a VLE. A national VLE roll-out that is not coupled with teacher professional development in distance and online pedagogies is unlikely to be successful. 


\subsection{Student readiness}

This section evaluates the ability of students, and their parents, to effectively utilise a VLE. The questions in Table 5 unpack the students unique needs, their device access and digital literacy levels, and their socio-economic status.

\section{Table 5. Discovery. Student Readiness}

\begin{tabular}{|c|c|c|}
\hline \multicolumn{3}{|c|}{ Discovery. Student Readiness } \\
\hline Questions & Options & Tick/Fill in \\
\hline \multirow{5}{*}{$\begin{array}{l}\text { What age groups will the platform } \\
\text { target? }\end{array}$} & Pre-primary students & $\square$ \\
\hline & Primary school students & $\square$ \\
\hline & Lower secondary school students & $\square$ \\
\hline & Upper secondary school students & $\square$ \\
\hline & Adult basic education students & $\square$ \\
\hline \multirow{4}{*}{$\begin{array}{l}\text { What are the varied } \\
\text { socio-economic backgrounds of } \\
\text { the target students? }\end{array}$} & From a low-income household & $\%$ \\
\hline & From a low- to middle-income household & $\%$ \\
\hline & From a middle-income household & $\%$ \\
\hline & From a high-income household & $\%$ \\
\hline \multirow{5}{*}{$\begin{array}{l}\text { What special needs do students } \\
\text { have? }\end{array}$} & Students who are hard of hearing or deaf & $\%$ \\
\hline & Students who are visually impaired or blind & $\%$ \\
\hline & $\begin{array}{l}\text { Students with special developmental needs, } \\
\text { e.g., Down syndrome, autism, dyslexia, and } \\
\text { processing disorders }\end{array}$ & $\%$ \\
\hline & $\begin{array}{l}\text { Students with physical disabilities, e.g., } \\
\text { muscular dystrophy, multiple sclerosis, } \\
\text { chronic asthma and epilepsy }\end{array}$ & $\%$ \\
\hline & $\begin{array}{l}\text { Students with special behavioural / emotional } \\
\text { needs, e.g., ADHD or bipolar disorder }\end{array}$ & $\%$ \\
\hline \multirow{4}{*}{$\begin{array}{l}\text { What level of support do students } \\
\text { need from their parents, if using } \\
\text { the VLE out-of-school? }\end{array}$} & Constant technical and educational support & $\square$ \\
\hline & Support setting up and connecting & $\square$ \\
\hline & Support understanding content & $\square$ \\
\hline & Standby support & $\square$ \\
\hline \multirow{2}{*}{$\begin{array}{l}\text { What percentage of students have } \\
\text { access to the listed devices? }\end{array}$} & No devices & $\%$ \\
\hline & Radio & $\%$ \\
\hline
\end{tabular}




\begin{tabular}{|c|c|c|}
\hline & Television & $\%$ \\
\hline & Feature phone & $\%$ \\
\hline & Smartphone & $\%$ \\
\hline & MP3 player & $\%$ \\
\hline & Tablet & $\%$ \\
\hline & Laptop & $\%$ \\
\hline \multirow{14}{*}{$\begin{array}{l}\text { What percentage of students have } \\
\text { digital or internet literacy in the } \\
\text { listed categories? }\end{array}$} & \multicolumn{2}{|l|}{ Mobile phone. Able to comfortably: } \\
\hline & navigate a feature phone & $\%$ \\
\hline & navigate a smartphone & $\%$ \\
\hline & use messaging applications & $\%$ \\
\hline & use email on mobile phone & $\%$ \\
\hline & browse the internet & $\%$ \\
\hline & $\begin{array}{l}\text { distinguish useful information from spam, } \\
\text { advertisements and misinformation }\end{array}$ & $\%$ \\
\hline & \multicolumn{2}{|l|}{ Laptop / Desktop. Able to comfortably: } \\
\hline & use a keyboard and mouse & $\%$ \\
\hline & use word processor and spreadsheets & $\%$ \\
\hline & browse the internet & $\%$ \\
\hline & use email on laptop / desktop & $\%$ \\
\hline & $\begin{array}{l}\text { Distinguish useful information from spam, } \\
\text { advertisements and misinformation }\end{array}$ & $\%$ \\
\hline & no digital or internet literacy & $\%$ \\
\hline \multirow{5}{*}{$\begin{array}{l}\text { What is the educational level of } \\
\text { the parents? }\end{array}$} & Completed primary school & $\%$ \\
\hline & Completed secondary school & $\%$ \\
\hline & Completed post-school diploma & $\%$ \\
\hline & Completed undergraduate studies & $\%$ \\
\hline & Completed postgraduate studies & $\%$ \\
\hline \multirow{5}{*}{$\begin{array}{l}\text { What percentage of parents have } \\
\text { digital or internet literacy in the } \\
\text { listed categories? }\end{array}$} & \multicolumn{2}{|l|}{ Mobile phone. Able to comfortably: } \\
\hline & navigate a feature phone & $\%$ \\
\hline & navigate a smartphone & $\%$ \\
\hline & Use messaging applications & $\%$ \\
\hline & Use email on mobile phone & $\%$ \\
\hline
\end{tabular}




\begin{tabular}{|l|l|}
\hline & browse the internet \\
\hline & $\begin{array}{l}\text { distinguish useful information from spam, } \\
\text { advertisements and misinformation }\end{array}$ \\
\hline & Laptop / Desktop. Able to comfortably: \\
\hline use a keyboard and mouse & $\%$ \\
\hline use word processor and spreadsheets & $\%$ \\
\hline browse the internet & $\%$ \\
\hline use email on laptop / desktop & $\%$ \\
\hline
\end{tabular}

The age group of students that the VLE is being designed for, influences the way VLE content and user interfaces should be designed. As mentioned previously, if pre-primary or primary school students are the target group, then parents' involvement will need to be considered more in the design. In this case the parents ability to support their learners technologically and pedagogically is important. If parents themselves have low education levels, it will be harder for them to support their children. Similarly, if parents have low digital literacy levels, they may struggle to give their children the technical support they need.

The socio-economic background of the students is important to note as it links to the likelihood of owning a device and being able to buy data. Students from low-to-middle-income homes are likely to need more support. Similarly, children with special needs will likely need more support, tailored according to their needs. There are also many special needs children who are not registered at school. If designed appropriately with features to support differently-abled children, a VLE could provide a unique opportunity to extend access to education to these marginalised groups. 


\subsection{Content readiness}

Beyond looking at infrastructure and users of the VLE, education implementers need to consider how to procure curriculum-aligned content. In general, implementers should draw on scaffolded curriculum-aligned content repositories where possible. Table 6 outlines various questions to investigate whether there is sufficient digitised content ready in the formats that it is needed in.

\section{Table 6. Discovery. Content Readiness}

\begin{tabular}{|c|c|c|}
\hline \multicolumn{3}{|c|}{ Discovery. Content Readiness } \\
\hline Questions & Options & Tick \\
\hline \multicolumn{3}{|l|}{ Which grades do you plan to put on the VLE? } \\
\hline \multicolumn{3}{|l|}{ What subjects do you plan to put on the VLE? } \\
\hline \multicolumn{3}{|l|}{$\begin{array}{l}\text { What language(s) do you intend the content and } \\
\text { content delivery to be in? }\end{array}$} \\
\hline \multirow{5}{*}{$\begin{array}{l}\text { How much of the national curriculum is already in a } \\
\text { digitised version? }\end{array}$} & $0 \%-20 \%$ & $\square$ \\
\hline & $20 \%-40 \%$ & $\square$ \\
\hline & $40 \%-0 \%$ & $\square$ \\
\hline & $60 \%-80 \%$ & $\square$ \\
\hline & $80 \%-00 \%$ & $\square$ \\
\hline \multirow{5}{*}{$\begin{array}{l}\text { How much of the national curriculum is already in a } \\
\text { digitised version in the selected languages? }\end{array}$} & $0 \%-20 \%$ & $\square$ \\
\hline & $20 \%-40 \%$ & $\square$ \\
\hline & $40 \%-60 \%$ & $\square$ \\
\hline & $60 \%-80 \%$ & $\square$ \\
\hline & $80 \%-100 \%$ & $\square$ \\
\hline \multirow{3}{*}{ What types of digitised content is already available? } & Learning material & $\square$ \\
\hline & Exercises & $\square$ \\
\hline & Quizzes and assessments & $\square$ \\
\hline
\end{tabular}




\begin{tabular}{|c|c|c|}
\hline & Other & $\square$ \\
\hline \multirow{5}{*}{$\begin{array}{l}\text { What formats is the currently available, digitised } \\
\text { content in? }\end{array}$} & Text & $\square$ \\
\hline & Images, figures or charts & $\square$ \\
\hline & Interactive HTML applications & $\square$ \\
\hline & Videos & $\square$ \\
\hline & Other & $\square$ \\
\hline \multirow{2}{*}{$\begin{array}{l}\text { Do you have content that can be used on multiple } \\
\text { modalities (e.g., print, radio, television and online)? }\end{array}$} & Yes & $\square$ \\
\hline & No & $\square$ \\
\hline \multirow{3}{*}{$\begin{array}{l}\text { How similar is your national curriculum to that of } \\
\text { other countries? }\end{array}$} & Very similar & $\square$ \\
\hline & Somewhat similar & $\square$ \\
\hline & Not similar at all & $\square$ \\
\hline \multicolumn{3}{|l|}{$\begin{array}{l}\text { What open education resources exist that are } \\
\text { aligned with, or can be aligned with, the national } \\
\text { curriculum? }\end{array}$} \\
\hline \multicolumn{3}{|l|}{$\begin{array}{l}\text { What new digitised, curriculum-aligned content do } \\
\text { you require for each subject and grade? }\end{array}$} \\
\hline \multirow{3}{*}{$\begin{array}{l}\text { Do you have a team of education specialists and } \\
\text { content designers to curate and nationally align } \\
\text { content? }\end{array}$} & Yes & $\square$ \\
\hline & $\begin{array}{l}\text { We are in the process of building } \\
\text { a team }\end{array}$ & $\square$ \\
\hline & No & $\square$ \\
\hline \multirow{4}{*}{$\begin{array}{l}\text { How much time would it take to prepare all the } \\
\text { types of digital content needed, in the various } \\
\text { formats needed, for all the subjects and grades, } \\
\text { such that they are ready for uploading to the VLE? }\end{array}$} & $0-3$ months & $\square$ \\
\hline & $3-6$ months & $\square$ \\
\hline & $6-12$ months & $\square$ \\
\hline & 12-18 months & $\square$ \\
\hline
\end{tabular}


Before rolling out a national VLE, it is important to determine whether there is sufficient digitised content available that is aligned with the national curriculum. This task is expanded when considering the various languages that content needs to be available in, to meet the diverse language needs of the population. ${ }^{11}$ By only selecting the main languages of the country, students that come from minority language groups will be further marginalised.

If content is digitised, it does not mean that it is ready to be uploaded on the VLE. For example, a curriculum-aligned digital textbook needs to be broken down into lessons and exercises so that scaffolded learning can take place. Multiple formats also need to be used so that information is relayed to students in different ways. Thus, it may mean that content from a textbook needs to be transformed into another content format. Different types of content such as exercises and quizzes are needed to both formatively and summatively assess learner progress.

After evaluating what already exists, and how the existing content needs to be adapted and developed, major gaps can be identified. A team of curriculum specialists and content designers needs to work together to adapt and curate the existing content, as well as create new content to fill in the gaps. We highly recommend making use of open educational resources first before creating new content. If this content does not exactly align with the national curriculum, it can be adapted to do so. It is thus worth searching open educational resource repositories first. Additionally, through identifying other countries that have similar national curriculums, open educational resources from those countries can also be reused.

While the questionnaire asks how long it will take to create all the content needed for the VLE, the agile approach recommends developing content incrementally. The following section unpacks how the content and the VLE can be developed iteratively.

\footnotetext{
${ }^{11} \mathrm{~A}$ broad range of documents reviewing available content is available in our evidence library here: https://docs.edtechhub.org/lib/?featured=BFS3UXT4\&sort=date desc
} 


\section{Iterative development: Alpha, Beta and Live}

Having completed the first iteration (discovery) we now consider the next iterations.

\subsection{Alpha}

The alpha phase is where ideas and approaches are explored through concrete prototypes. Having unpacked some of the assumptions in the discovery phase, the alpha phase is meant to test potential prototypes (i.e., prototypes for services or products, such as VLEs or virtual learning opportunities) with the minimum effort required. Multiple ideas should be explored here without too much investment. The aim is to evaluate which products and / or services best meet the users' needs.

\subsubsection{Content}

To test and develop a minimum variable product, that is, the most basic version of the VLE, only a small amount of content needs to be curated, nationally-aligned, and uploaded onto a VLE. This could be done for one subject of one grade.

Before commencing with content curation, research should be done to evaluate which Open Educational Resources already exist (within the local context), and which Open Educational Resources can be reused or adapted from other contexts. In this phase, making use of existing content may be the best approach to first gauge whether the content meets the users needs.

During this content curation process, certain observations should be made. The education implementers should monitor how long it takes to curate the content and upload it onto the VLE. They should also gauge whether the content curation team needs to be expanded or reduced, or if additional skillsets are needed to improve the curation process.

\subsubsection{Platform and configuration}

In the alpha phase, multiple VLE platforms (or alternatives to VLEs such television broadcasting) that meet different needs can be trialled. For example, asynchronous and synchronous platforms can be trialled as well as offline and online modes.

In bandwidth constrained settings, Kolibri is perhaps one of the best options. To test Kolibri, not much hardware needs to be purchased. Kolibri can be hosted on a Raspberry Pi to test how well it works in different contexts.

\subsubsection{Trialling}

Once the content is curated and uploaded onto the VLE platforms that will be tested, trialling can begin. To assess whether the VLE prototypes meet users needs, it needs to be tested in differing contexts. Different scenarios can be tested to see how a VLE would work in school or out of school. We recommend trialling the VLE in a variety of settings (e.g., within five schools and within five communities) to ascertain which VLE configurations best meet the user needs and addresses the problem. For example, the following configurations should be explored: 
- Schools, communities and households in urban, rural and remote areas;

- Schools, communities and households in different provinces / districts;

- Schools and communities and households with differing levels of electricity;

- Schools and communities and households with differing levels of internet access;

- Female teachers and male teachers;

- Teachers with different levels of teacher professional development;

- Teachers with different levels of digital literacy;

- Female students and male students;

- Students with different levels of digital literacy;

- Students with special needs.

In addition to testing VLE configurations, the content form and type should be evaluated. Different types of content should be included to determine what best suits the users. The content should consider the technological constraints of the users and their learning preferences.

As users may be completely unfamiliar with the concept of a VLE, this will need to be explained to them. A user guide which explains how the VLE should be used by each user could be distributed. In particular, teachers will need teacher professional development in how to use the VLE. Teacher professional development in distance and online pedagogies should not be seen as separate or parallel to rolling out a national VLE, but in fact one of the key components.

In this phase - as with all phases - user feedback is crucial. Focus groups can be set up with headteachers, teachers, parents and students for them to provide feedback on the VLE. Surveys can also be embedded into the lessons to get more structured feedback. Additionally, observations can be done in schools where the VLE is used for blended learning.

At the end of the alpha phase, the information gathered should be evaluated. The evaluation should determine which VLE scenarios best address the problem and meet the needs and contexts of the users, if they do at all.

\subsection{Beta - Trial with 100 schools}

In the beta phase, the number of test sites will increase. This number can incrementally increase to around 100 schools / communities. Around 100 schools are needed by the end of the beta phase in order to allow for proper and meaningful evaluation at a reasonable scale.

After reflection on the various test cases, one VLE platform should be chosen. Further curated content should be developed and uploaded onto this VLE. As content may take months to develop, new content could be rolled out incrementally to gain feedback early on. Importantly, any feedback on the content from the alpha phase should be incorporated. For example, users may want fewer videos or more exercises. They may find the accents of the speakers difficult to follow. They may find the vocabulary too challenging. Content designers need to be adaptive to these user needs and design accordingly. Teacher Professional Development also needs to be developed and tested in conjunction with this. 
In terms of the platform, further user feedback should also be incorporated. For example, user interface issues not discovered during alpha may surface. More sign-posting may be needed. Given the larger group of teachers (compared to the alpha), teachers within the larger, more diverse group might be struggling to set lessons and need further guidance and professional development. Parents might be struggling to support their children's learning at home. This feedback should inform how the VLE is further developed as well as how supporting teacher professional development is arranged.

By the end of the beta phase all the content should be developed for the subjects and grades that the VLE was meant for. These should be tested and redesigned based on any feedback received. All kinks and bugs should be fixed before going national.

\subsection{Live - Go national}

In this phase, the VLE is ready to go national. This means that teachers nationally should be receiving teacher professional development on how to use the VLE. As you go from beta to live, you need to carefully consider infrastructure requirements (including server capacity) to manage large numbers of users. There are advantages and disadvantages to (de-)centralised systems. For example, using a decentralised offline configuration (as with Kolibri), the need for connectivity is avoided as each school or community space has its own local server. If connectivity is available but intermittent, these servers can still be updated and managed remotely. However, for an offline environment like this, a larger amount of manual work is needed to set up a VLE in each school and selected community spaces. In all cases, these local installations will need to be maintained and protected from theft. We do note that in the early days of internet-use in schools in the UK, the fact that the internet did not work reliably was a significant deterrent to teachers using the internet. We would therefore only recommend a fully-online approach if the infrastructure outside the school is reliable - this is rarely the case in low-income countries.

While this VLE note has not directly focused on costs and budgeting, the following line items should be taken into account:

- Researchers to conduct research into multiple platforms, open educational resources and user needs;

- A content curation team consisting of curriculum specialist and content designers;

- A national teacher professional development programme;

- Servers and infrastructure needed;

- Staff to deliver and set up servers in schools and / or community spaces around the country;

- Maintenance of the VLE and the supporting infrastructure.

\subsection{Timescale}

The timescale for development and roll-out depends on multiple factors. Factors include how many grades and subjects the VLE is for, how much content is digitised and 
curated, and how prepared teachers are to teach using a VLE. If a lot of progress has already been made on these fronts, a VLE could be rolled out sooner rather than later. While the discovery phase may be relatively quick (around 3 months), the alpha phase could take up to a year to evaluate various prototypes. Similarly, the beta phase could also take up to a year to incrementally scale and develop the VLE. This is shown in Figure 13.

Figure 13. Expected timescale for phases

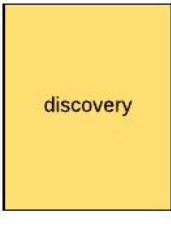

3 months

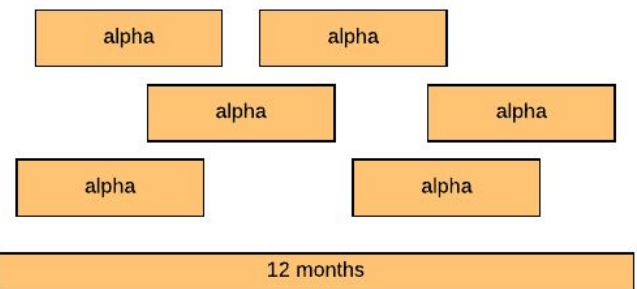

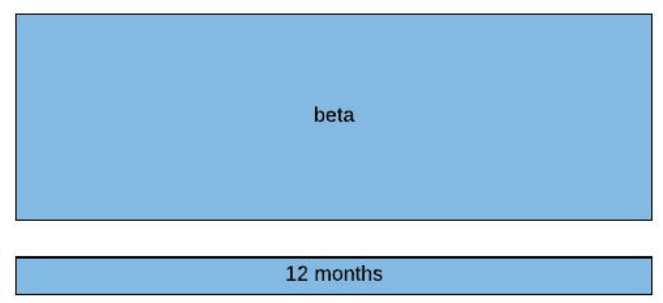

12 months

If content is not ready and teachers are not prepared — which is the most realistic case - rolling out a VLE should be seen as a medium-term goal over a two-and-a-half-year period.

\section{Summary}

This note uses an agile design thinking approach to unpack the considerations that need to be taken before rolling out a VLE. The purpose of this note is to ensure that education planners are fully aware of what rolling out a VLE entails. Furthermore, it serves to properly ascertain whether a VLE is in fact an effective intervention to address the educational needs of the country. Six questionnaires are included in the discovery phase to determine:

- what the problem being addressed is,

- what the user needs are,

- whether educators and students are ready for a VLE,

- whether there is quality digitised content ready for the VLE.

Following the agile approach, iterative development is suggested where small prototypes testing different use cases are first implemented in the alpha phase. After reflection, one VLE platform should be chosen for the beta phase. In this phase, the VLE can be piloted in up to 100 schools / community spaces and can be tested with a wide range of curated content. Importantly, a teacher professional development plan needs to be rolled out in conjunction with the VLE roll-out. Once the beta version is tested and is working without glitches, the VLE can be rolled out nationally. Once rolled out nationally, continuous maintenance of the VLE and infrastructure will be needed in addition to continuous teacher professional development. 


\section{References}

Adam, T., McBurnie, C., \& Haßler, B. (2020). Rolling out a national virtual learning environment (EdTech Hub Helpdesk Request No. 22).

https://doi.org/10.5281/zenodo.3406132

Cable. (2020). Worldwide Mobile Data Pricing League | Cost of 1GB in 230 countries. Cable. https://www.cable.co.uk/mobiles/worldwide-data-pricing/

Centre for International Development. (2018). PDIA Toolkit: A DIY Approach to Solving Complex Problems. Harvard University. https://bsc.cid.harvard.edu/files/bsc/files/pdiatoolkit ver 1 oct 2018.pdf

Haßler, B. (2020, April 16). Continue or reboot? Overarching options for education responses to COVID-19 in low- and middle-income countries. https://doi.org/10.5281/zenodo.3753513

Haßler, B., \& Jackson, A. M. (2010). Bridging the Bandwidth Gap: Open Educational Resources and the Digital Divide. IEEE Transactions on Learning Technologies, 3(2), 110-115. https://doi.org/10/dxgcg5

Haßler, B., Khalayleh, A., \& McBurnie, C. (2020). A five-part education response to the COVID-19 pandemic (EdTech Hub Helpdesk Response No. 5). https://doi.org/10.5281/zenodo.3756012

Khalayleh, A. (2020, April 3). Arabic version of Design Thinking for Educators - Open Development \& Education. https://opendeved.net/2020/04/03/arabic-version-of-design-thinking-for-educator s/

Le Nestour, A., Moscoviz, L., \& Mbaye, S. (2020). Phone survey on the Covid crisis in Senegal. Centre for Global Development. https://dataverse.harvard.edu/file.xhtml?persistentld=doi:10.7910/DVN/9XE95F/95 RW9C\&version=3.0

McBurnie, C. (2020). The use of virtual learning environments and learning management systems during the COVID-19 pandemic (EdTech Hub Helpdesk Request No. 7). https://doi.org/10.5281/zenodo.3805843

McBurnie, C., Adam, T., Kaye, T., \& Haßler, B. (2020). Zero-rating educational content in low- and middle-income countries (EdTech Hub Helpdesk Response No. 8). https://doi.org/10.5281/zenodo.3784940

McBurnie, C., \& Haßler, B. (2020, July 12). Is there learning continuity during the COVID-19 pandemic? Six Lessons. https://doi.org/10.5281/zenodo.3930934

Schurr, M. (2013). Design Thinking for Educators. https://designthinkingforeducators.com/design-thinking/ 
UNICEF, UNESCO, WHO, UNODC, ITU, End Violence Against Children, \& We Protect Global Alliance. (2020). COVID-19 and Its Implications for Protecting Children Online. https://inee.org/system/files/resources/COVID-19\%20and\%20Its\%20Implications\% 20for\%20Protecting\%20Children\%200nline.pdf 